The FASEB Journal express article 10.1096/fj.02-0193fje. Published online June 21, 2002.

\title{
Airway hyperresponsiveness, but not airway remodeling, is attenuated during chronic pulmonary allergic responses to Aspergillus in CCR4-/- mice
}

Jane M. Schuh, ${ }^{*}$ Christine A. Power, ${ }^{\dagger}$ Amanda E. Proudfoot, ${ }^{\dagger}$ Steven L. Kunkel, ${ }^{*}$ Nicholas W. Lukacs, ${ }^{*}$ and Cory M. Hogaboam*

*Department of Pathology, University of Michigan Medical School, Ann Arbor, Michigan, USA, and ${ }^{\dagger}$ Serono Pharmaceutical Research Institute, Geneva, Switzerland

Corresponding author: Cory M. Hogaboam, Department of Pathology, University of Michigan Medical School, Room 5214, Med Sci I, 1301 Catherine Road, Ann Arbor MI, 48109-0602, USA. E-mail: hogaboam@med.umich.edu

\section{ABSTRACT}

The role of CC chemokine receptor 4 (CCR4) during the development and maintenance of Th2type allergic airway disease is controversial. In this study, we examined the role of CCR4 in the chronic allergic airway response to live Aspergillus fumigatus spores, or conidia, in A. fumigatussensitized mice. After the conidia challenge, mice lacking CCR4 (CCR4-/- mice) exhibited significantly increased numbers of airway neutrophils and macrophages, and conidia were more rapidly eliminated from these mice compared with control CCR4 wild-type (CCR4+/+) mice. Significant airway hyperresponsiveness to intravenous methacholine was observed at day 3 in CCR4-/- mice, whereas at days 7 and 30, airway hyperresponsiveness was attenuated in these mice compared with control mice. A major reduction in peribronchial and airway eosinophilia was observed in CCR4-/- mice at all times after conidia challenge in contrast to CCR4+/+ mice. Further, whole lung levels of interleukin (IL) 4 and IL-5 were significantly increased in CCR4-/mice at day 3, whereas these Th2 cytokines and IL-13 were significantly decreased at day 30 in CCR4-/- mice compared with their wild-type counterparts. Peribronchial fibrosis and goblet cell hyperplasia were similar in both groups of mice throughout the course of this model. In summary, CCR4 modulates both innate and acquired immune responses associated with chronic fungal asthma.

Key words: Aspergillus fumigatus $\bullet$ asthma $\bullet$ allergy $\bullet$ airway hyperreactivity $\bullet$ inflammation

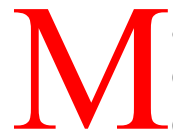

acrophage-derived chemokine (MDC/CCL22) and thymus- and activation-regulated chemokine (TARC/CCL17) were initially identified in the thymus $(1,2)$, but both CC chemokines are expressed in other tissues including the skin $(3,4)$ and lung $(5-7)$. Via their ability to bind and activate CC chemokine receptor 4 (CCR4) $(8,9)$, both chemokines affect the movement of several inflammatory and immune cells, including macrophages, dendritic cells, natural killer cells, and Th2 subsets of T cells (reviewed in ref 10). Many of the same CCL22- and CCL17-responsive cells also generate substantial levels of both CC chemokines after stimulation by a pathogen by-product (i.e., lipopolysaccharide [LPS]) and/or cytokine (11). 
In addition, the resistance of mice lacking CCR4 (CCR4-/- mice) to LPS-induced mortality suggests a unique role for this receptor in innate immune responses (12). More recently, it was shown that the de novo generation of CCL22 by dendritic cells resulted in the firm adhesion between these cells and antigen-primed CCR4-positive T cells (13).

Given the variety of cells that respond to them and the array of factors that induce their expression, it is not surprising that CCL22 and CCL17 are intricately involved in many aspects of immunoregulation, ranging from host defense to Th2-driven allergic responses (reviewed in refs 14, 15). For example, CCL22 is protective in a murine model of septic peritonitis because of its enhancement of macrophage phagocytic and killing activities as well as the induction of both a respiratory burst and the release of lysosomal enzymes from these cells (16). CCL22 (17) and CCL17 (18) have also been associated with acute reactions in asthmatic responses in mice induced by ovalbumin (OVA). Similarly, in a study of allergen-challenged asthmatics, staining revealed up-regulation of CCL22 and CCL17 on airway epithelial cells, whereas T cells in the airway mucosa stained prominently for CCR4 (19).

Although CCL22, CCL17, and CCR4 are associated with Th2-mediated allergic and asthmatic airway disease characterized by airway hyperresponsiveness and airway eosinophilia, recent studies with CCR4-/- mice indicate that acute OVA-induced allergic airway disease is not affected by the absence of CCR4 (12). Because acute and chronic forms of allergic airway inflammation are profoundly different, we examined the role of CCR4 in the context of chronic allergic airway disease induced by the introduction of live Aspergillus fumigatus spores, or conidia, into the airways of A. fumigatus-sensitized mice (20). The murine Aspergillus model of allergy is characterized by an intricate interplay between the innate immune responses directed against the conidia $(21,22)$ and the Th2-mediated events that modulate peribronchial eosinophilia, airway hyperresponsiveness, and airway remodeling $(23,24)$. The present study demonstrated that CCR4-/- mice exhibit a very aggressive early antifungal response characterized by enhanced neutrophil function and increased macrophage numbers. At later times after the conidia challenge, A. fumigatus-sensitized CCR4-/- mice exhibited attenuated airway hyperresponsiveness and airway eosinophilia compared with similarly treated CCR4+/+ mice, although both groups exhibited similar degrees of airway remodeling.

\section{MATERIALS AND METHODS}

\section{Mice}

Drs. Christine Power and Amanda Proudfoot (Serono Pharmaceutical Research Institute, Geneva, Switzerland) provided breeding pairs of CCR4-/- mice, and a breeding colony was initiated and maintained under specific pathogen-free conditions in the University Laboratory of Animal Medicine facility. Prior approval for mouse usage in the present study was obtained from this facility. As previously described, CCR4-/- mice were born at the expected mendelian ratios and showed no evidence of abnormal growth patterns (12). Because CCR4-/- mice were on a C57BL/6 genetic background, C57BL/6 (CCR4+/+) mice (Jackson Laboratories, Bar Harbor, ME) were used as controls in the experiments. Sensitization of mice to a commercially available preparation of soluble $A$. fumigatus antigens was performed as previously described in detail (20). Briefly, mice received an intraperitoneal and a subcutaneous injection of soluble $A$. 
fumigatus antigens dissolved in incomplete Freund's adjuvant. Two weeks after the systemic sensitization, each mouse received a weekly intranasal challenge with A. fumigatus antigen to localize the allergic responsiveness to the airways. One week after the third intranasal challenge, each mouse received $5.0 \times 10^{6}$ A. fumigatus conidia suspended in $30 \mu 1$ of $0.1 \%$ Tween-80 via the intratracheal route (20).

\section{Measurement of bronchial hyperresponsiveness}

Immediately prior to and at days 3, 7, and 30 after the intratracheal A. fumigatus conidia challenge, bronchial hyperresponsiveness to methacholine (at a concentration of 420,520, or 625 $\mu \mathrm{g} / \mathrm{kg}$ ) was assessed via a Buxco plethysmograph (Buxco, Troy, NY) as previously described (20). Sodium pentobarbital (Butler, Columbus, OH; $0.04 \mathrm{mg} / \mathrm{g}$ of mouse body weight) was used to anesthetize mice before their intubation and ventilation with a Harvard pump ventilator (Harvard Apparatus, Reno, NV). Immediately after the assessment of airway hyperresponsiveness, bronchoalveolar lavage (BAL) was performed with $1 \mathrm{ml}$ of sterile normal saline. Approximately $500 \mu \mathrm{l}$ of blood was removed from each mouse and centrifuged at $6000 \mathrm{~g}$ for 10 min to yield serum. Finally, whole lungs were dissected from each mouse and snap frozen in liquid $\mathrm{N}_{2}$ for ELISA protein analysis or were fixed in $10 \%$ formalin for histological processing.

\section{Morphometric analysis of leukocyte accumulation in BAL samples}

Macrophages, neutrophils, eosinophils, and lymphocytes were quantified in BAL samples cytospun (Shandon Scientific, Runcorn, UK) onto coded microscope slides as previously described in detail (22). These slides were stained with Wright-Giemsa, and the average number of each cell type was determined after counting a total of 300 cells in 10-20 high-power fields $(\mathrm{HPF} ; 1000 \times)$ per slide. Approximately $1 \times 10^{5} \mathrm{BAL}$ cells were cytospun onto each slide to compensate for differences in cell retrieval.

\section{Measurement of myeloperoxidase}

Myeloperoxidase (MPO) is an enzyme found predominately in azurophilic granules of neutrophils that catalyzes the formation of hypochlorous acid. MPO is commonly used as an index of the activation state or presence of neutrophils in a variety of tissues. A commercially available MPO-specific ELISA was used to determine immunoreactive levels of MPO in whole lung samples per the manufacturer's instructions (Calbiochem, San Diego, CA). MPO levels were normalized to total protein levels by using the Bradford assay.

\section{ELISA analysis}

Levels of murine CCL22, CCL17, interleukin (IL) 4, IL-5, interferon $\gamma$ (IFN- $\gamma$ ), IL-13, macrophage inflammatory protein $1 \alpha / \mathrm{CCL} 3$, and monocyte chemoattractant protein-1 (MCP$1 /$ CCL2) were determined in 50- $\mu 1$ samples from whole lung homogenates by using a standardized sandwich ELISA technique. Each ELISA was screened to ensure the specificity of each antibody used. Recombinant murine cytokines or chemokines were used to generate the standard curves from which the concentrations present in the samples were derived. The limit of 
ELISA detection for each cytokine was consistently above $50 \mathrm{pg} / \mathrm{ml}$. Cytokine and chemokine levels were normalized to total protein levels with the Bradford assay. Serum levels of immunoglobulins E and G1 (IgE and IgG1) were analyzed by using complementary capture and detection antibody pairs for each immunoglobulin (BD Biosciences Pharmingen, San Diego, $\mathrm{CA}$ ), and an ELISA was performed according to the manufacturer's directions. Duplicate serum samples were diluted to 1:100 (IgE) or 1:1000 (IgG1), immunoglobulin levels in each assay were calculated from optical density readings at $492 \mathrm{~nm}$, and immunoglobulin concentrations were calculated from a standard curve generated by using recombinant versions of IgE or IgG1 (5$2000 \mathrm{pg} / \mathrm{ml})$.

\section{Soluble collagen analysis}

In the present study, soluble forms of collagen were measured in whole lung homogenates from both groups of mice via the Sircol Collagen Assay (Biocolor, Belfast, Ireland). We previously observed that results obtained with this assay are comparable to the standard hydroxyproline assay. This assay was developed from the Sirius Red-based histochemical procedure. The collagen levels in each sample were normalized to total protein levels by using the Bradford assay.

\section{Whole lung histological analysis}

Whole lungs from A. fumigatus-sensitized CCR4+/+ and CCR4-/- mice at days 3, 7, and 30 after A. fumigatus conidia challenge were fully inflated with $10 \%$ formalin, dissected, and placed in fresh formalin for $24 \mathrm{~h}$. Routine histological techniques were used to paraffin-embedded the entire lung, and 5- $\mu \mathrm{m}$ whole lung sections were stained with one of Gomori methanamine-silver (GMS), hematoxylin and eosin, periodic acid-Schiff (PAS), or Masson trichrome stains. Inflammatory infiltrates and structural alterations were examined around blood vessels and airways via light microscopy at a magnification of $1000 \times$. Morphometric analysis of peribronchial eosinophilia was conducted as previously described in detail (25).

\section{Spleen and lung cell culture and cytometric analysis}

The spleens and lungs of CCR4-/- and control mice were aseptically removed at day 30 after conidia challenge and were processed as previously described in detail (26). Briefly, lung tissues were pooled, macerated, shaken in $0.2 \%$ (w/v) collagenase (type IV) in RPMI medium with $10 \%$ FBS for $45 \mathrm{~min}$ at $37^{\circ} \mathrm{C}$, and washed in a balanced salt solution to remove aggregates. Both lung and spleen suspensions were treated with ammonium chloride to lyse red blood cells. The resulting cell suspensions were washed and counted with the aid of a hemocytometer. Ex vivo cell cultures were plated at a density of 2 million cells $/ \mathrm{ml}$ in Dulbecco's modified Eagle's medium supplemented with $15 \%$ FBS and antibiotics. The culture medium was used as the control as well as the diluent for each treatment antigen. One microgram of concanavalin A was added to the spleen or lung cells from CCR4-/- or CCR4+/+ mice. The cultures were incubated for $36 \mathrm{~h}$ at $37^{\circ} \mathrm{C}$ in $5 \% \mathrm{CO}_{2}$. Supernatants were removed for evaluation by ELISA, as described above. The remaining cells were fixed in $2 \%$ paraformaldehyde for $30 \mathrm{~min}$, the cells were counted with the use of a hemocytometer, and 500,000 of each cell type were transferred to clean tubes for staining. Fc binding was blocked via a 10-min incubation with anti-murine CD16/CD32 
(Fc $\gamma$ III/II receptor; BD Biosciences Pharmingen). The cells were then stained with anti-murine CD4, anti-murine CD8a, anti-murine CD19, anti-murine F4/80, or rat IgG2a isotype control (all BD Biosciences Pharmingen) for $30 \mathrm{~min}$ at $4{ }^{\circ} \mathrm{C}$ in PBS supplemented with $5 \%$ FCS. Each cell population was analyzed by flow cytometry (Beckman Coulter EPICS XL, Miami, FL). The isotype control was used to gate the population of interest and as the negative control. The total population of each cell type was corrected against the control, and total cell counts were calculated.

\section{Statistical analysis}

All results are expressed as a mean \pm standard error (SE). ANOVA and the Bonferroni test for multiple comparisons were used to determine statistical significance in both groups at various times after the conidia challenge; $P<0.05$ was considered statistically significant.

\section{RESULTS}

Levels of CCR4 agonists CCL22 and CCL17 were significantly elevated at days 3 and 7, but not day 30, after conidia challenge in $A$. fumigatus-sensitized CCR4+/+ mice

Before the conidia challenge, whole lung baseline levels of CCL22 (Fig. 1A) and CCL17 Fig. $\underline{1 B}$ ), both CCR4 ligands, were similar in CCR4-/- and CCR4+/+ mice, as shown by the dashed lines. At days 3 and 7 after the conidia challenge, whole lung levels of CCL22 and CCL17 in control mice were significantly elevated above baseline levels and those measured in CCR4-/whole lung samples. However, at day 30 after conidia, whole lung expression of both CCR4 ligands had returned to near baseline levels in CCR4+/+ mice. These data suggested that CCL22 and CCL17 were involved in the early inflammatory pulmonary response initiated by the introduction of $A$. fumigatus conidia into A. fumigatus-sensitized wild-type mice. Interestingly, in the absence of CCR4, both CCL22 and CCL17 levels did not change during the course of the conidia challenge, suggesting that CCR4 expression may be required to stimulate increased synthesis of its ligands during pulmonary responses to Aspergillus. This contrasts with our findings from CCR2-/- mice in which the levels of CCL2 were enhanced in the absence of that chemokine receptor (21).

\section{A. fumigatus conidia were rapidly cleared from the lungs of $A$. fumigatus-sensitized CCR4-/- mice}

GMS-stained whole lung sections from CCR4-/- and CCR4+/+ mice were examined at various times after conidia challenge to determine differences in clearance of Aspergillus conidia. GMS stains the polysaccharide components from the fungus cell wall black in histological samples. At day 3 after conidia challenge, GMS-positive cells were present in lung sections from CCR4+/+ mice (Fig. 2A) and CCR4-/- mice (Fig. 2B). At day 7 after conidia challenge, GMS-positive mononuclear cells were detected in CCR4+/+ mice (Fig. 2C), but GMS staining was largely absent from CCR4-/- mice (Fig. 2D). At day 30 after conidia challenge, whole lungs from CCR4+/+ mice contained GMS-positive cells (Fig. 2E), whereas no GMS-stained mononuclear cells were observed in CCR4-/- mice (Fig. 2F). These observations suggested that the lack of 
CCR4 enhanced the clearance of A. fumigatus conidia and cell wall components from the airways of challenged mice.

Macrophage and neutrophil numbers were increased in the airways of sensitized CCR4-/mice challenged with $A$. fumigatus conidia

Because both macrophages and neutrophils participate in host defense against Aspergillus (27, 28), we next examined whether these cell populations were altered in A. fumigatus-sensitized CCR4-/- mice after the conidia challenge. As shown in Fig. 3, significantly greater numbers of neutrophils were detected in BAL samples removed from CCR4-/- mice compared with CCR4+/+ mice at days 3 and 7 after conidia. Significant increases in macrophage numbers in BAL samples from CCR4-/- mice compared with similar samples from CCR4+/+ mice were observed at all three times examined after the conidia challenge. Even more dramatic was the increased level of MPO, a specific marker of neutrophil activation (29), present in whole lung samples from CCR4-/- mice when compared with CCR4+/+ mice at days 3 and 7 after conidia (Fig. 4). Taken together, these data suggested that the increased numbers of inflammatory cells having potent antifungal properties enhanced and/or accelerated the clearance of conidia from the airways of CCR4-/- mice.

Temporal changes in levels of tumor necrosis factor $\alpha$ (TNF- $\alpha)$ and IL-10 were observed after conidia challenge in sensitized CCR4-/- mice

We next examined whether whole lung levels of TNF- $\alpha$ and IL-10 differed between CCR4+/+ and CCR4-/- mice during the course of chronic fungal asthma. Interest in these cytokines stemmed from previous studies that demonstrated a major innate antifungal role for TNF- $\alpha$ (30), and the immunomodulatory role of IL-10 during pulmonary responses to Aspergillus. With regard to IL-10, it has been shown to suppress both the Th1- and Th2-mediated lung responses during allergic responses to A. fumigatus (31), it increases the phagocytic activity of alveolar macrophages (32), and its presence during systemic aspergillosis infection promotes lethality $(33,34)$. Whole lung levels of TNF- $\alpha$ are shown in Fig. $5 A$ and those of IL-10, in Fig. $5 B$. Whole lung TNF- $\alpha$ levels did not differ between the two groups of mice at days 3 and 7 after conidia, but levels of this cytokine were significantly lower in the CCR4-/- group compared with the CCR4+/+ group at day 30 after conidia challenge (Fig. 5A). Differences in IL-10 levels between the two groups of mice were observed at days 3 and 30, but not day 7, after conidia challenge, in that whole lungs from CCR4-/- mice contained significantly more IL-10 at day 3 and significantly less IL-10 at day 30 after conidia challenge compared with CCR4+/+ mice (Fig. $\underline{5 B})$. These data suggested that the enhanced antifungal immune activation in the CCR4-/- was presumably not a consequence of increased TNF- $\alpha$ activation, but the increased presence of IL10 at day 3 after conidia may have contributed to the initial immune response against the Aspergillus spores through its enhancement of macrophage phagocytosis (32).

Total serum IgE and IgG1 levels were significantly increased in CCR4-/- mice at early time points after $A$. fumigatus conidia challenge

Increased IgE and IgG1 levels are hallmarks of hypersensitivity to $A$. fumigatus $(35,36)$. Total serum levels of IgE are shown in Fig. 6A. CCR4-/- mice mounted a marked allergic response to 
Aspergillus, as shown by the markedly elevated levels of $\operatorname{IgE}$ at days 3 and 7 after conidia challenge. IgG1 levels are shown in Fig. $6 \mathrm{~B}$. Although the levels of IgG1 in CCR4-/- mice were similar to controls at days 7 and 30, the day 3 level was nearly seven times that of the CCR4+/+ control mice, which underscores the swift initial Th2-type response seen in these mice. However, this response was not maintained in the CCR4-/- mice: IgE and IgG1 levels dropped to at or below controls by day 30 .

\section{Airway hyperresponsiveness was not maintained in CCR4-/- mice after conidia challenge}

We previously observed that the introduction of conidia into mice sensitized with soluble $A$. fumigatus antigens results in persistent airway hyperresponsiveness to the nonspecific bronchoconstrictor methacholine (20). In the present study, airway hyperresponsiveness to a methacholine challenge was measured in A. fumigatus-sensitized CCR4+/+ and CCR4-/- mice at various times after conidia challenge (Fig. 7). The dashed line indicates baseline values for airway resistance prior to the bronchoconstrictor administration. Three doses of methacholine were tested in this experiment (see Materials and Methods), and the data shown in Fig. 7were generated by using a $520 \mu \mathrm{g} / \mathrm{kg}$ dose. This dose of methacholine caused a minor twofold increase in the airway resistance response in nonsensitized mice, but it promoted a maximal increase in airway resistance in A. fumigatus-sensitized mice. At day 3 after conidia challenge, the methacholine-induced airway resistance was significantly greater in CCR4-/- mice than in CCR4+/+ mice. At day 7, the average airway resistance in CCR4-/- mice was lower than that measured in CCR4+/+ mice, although this difference did not reach statistical significance. At the final time point (day 30), airway resistance values were significantly lower in CCR4-/- mice compared with the wild-type controls (Fig. 7). Overall, in CCR4-/- mice, airway responsiveness to methacholine peaked at day 3 after conidia challenge and diminished to near baseline at later stages.

\section{Lymphocyte and eosinophil recruitment into and around the airways of sensitized CCR4-/- mice was altered after conidia challenge}

T lymphocytes and eosinophils are major cellular effectors in the protracted asthmatic responses observed in a large subset of patients with hypersensitivity to A. fumigatus antigens (36) (37). Clinical and experimental data suggest that a Th2-type response utilizing IL-4, IL-5, and IL-13 is the major predisposing factor for the development of allergic responses to Aspergillus in the lung (38). Quantification of eosinophils and lymphocytes in BAL samples revealed obvious differences between control and wild-type mice at days 3, 7, and 30 after the conidia challenge (Fig. 8). At day 3, BAL samples from CCR4-/- mice contained a greater than twofold increase in T lymphocytes when compared with BAL samples from CCR4+/+ mice. This difference was not observed at day 7, when similar numbers of $\mathrm{T}$ lymphocytes were detected in BAL samples from both groups of mice. The relative number of T lymphocytes was lower at day 30 in CCR4/- mice compared with the control wild-type group.

Eosinophilic inflammation around the airways poses a particularly serious problem because of the disruptive proteolytic enzymes released by these cells upon degranulation (38). No eosinophils were observed in the BAL of either CCR4-/- or CCR4+/+ mice prior to the conidia challenge. However, 3 days after the introduction of spores, CCR4+/+ mice had a striking 
eosinophil presence, although CCR4-/- mice displayed significantly fewer numbers of these cells in the BAL ( $\underline{\text { Fig. 8) }}$ ). At days 7 and 30 after conidia, the eosinophil numbers in the BAL from CCR4-/- mice were again consistently lower than those detected in similar samples from CCR4+/+ mice. To further investigate the impact of the absence of CCR4 on eosinophil recruitment during chronic fungal asthma, eosinophils were enumerated around the airways of both groups of mice at various times after conidia challenge. Figure 9 illustrates differences in peribronchial eosinophil numbers at days 3, 7, and 30 after conidia challenge between CCR4-/mice and their wild-type counterparts. Peribronchial eosinophil numbers were significantly lower CCR4-/- mice compared with the wild-type group at all times. Taken together, these data suggest that although eosinophils are recruited to the lungs early in the course of the infection, they are not induced to remain in the airways where they would affect airway hyperresponsiveness.

\section{Temporal changes in Th2-type cytokine levels were observed after conidia challenge in sensitized CCR4-/- mice}

Given the major alterations in eosinophil and lymphocyte numbers in the BAL samples from CCR4-/- mice, we next examined whether the whole lung levels of cytokines that regulate the activation of these cell types were altered. IL- 4 and IFN- $\gamma$ are characteristically described as Th2- and Th1-type cytokines, respectively (39). IL-5 modulates the activation and survival of eosinophils (40), and IL-13 mediates airway hyperresponsiveness, eosinophil recruitment, mucus overproduction $(41,42)$, and subepithelial fibrosis (43). We previously observed that IL-13, more so than IL-4, has a major role in the appearance and maintenance of all of these features in the chronic fungal asthma model $(26,44,45)$. Temporal changes are shown for levels of IL-4 (Fig. 10A), IL-5 (Fig. 10B), IFN- $\gamma$ (Fig. 10C), and IL-13 (Fig. 10D) in whole lung homogenates from both groups of mice. In CCR4-/- mice, levels of both IL-4 and IL-5 were significantly increased at day 3 after conidia challenge but were significantly decreased at day 30 after conidia challenge when compared with those in CCR4+/+ mice. Whole lung levels of IFN- $\gamma$ were significantly elevated in CCR4-/- mice at day 3 after conidia challenge; however, levels of this cytokine did not differ between the two groups at later times (Fig. 10C). IL-13 levels were significantly different between the CCR4+/+ and CCR4-/- groups only at day 30 after conidia challenge $(\underline{\text { Fig. } 10 D})$. These data indicate that the initially strong Th2-type pulmonary cytokine profile associated with allergic airway responses to Aspergillus was not maintained in the absence of CCR4 in the later stages of the model.

Flow cytometric analysis of immune cells from lung and spleen cell preparations revealed a marked reduction in macrophages expressing $\mathrm{F} 4 / 80$ at day 30 after conidia challenge in CCR4-/- mice

We next examined the overall differences in $\mathrm{T}$ and $\mathrm{B}$ cell numbers in whole lung and spleen samples from CCR4+/+ and CCR4-/- mice at day 30 after conidia challenge. This study was initiated to determine whether the lack of CCR4 overtly affected the recruitment of lymphocytes into the lungs of mice with chronic fungal asthma. Dispersed lung (Fig. 11A) and spleen (Fig. $\underline{11 B}$ ) cells from CCR4+/+ and CCR4-/- mice at day 30 after the conidia challenge were analyzed by flow cytometry. Figure 11 shows that the numbers of T lymphocytes (as represented by CD4- 
and CD8-positive cells) and CD19-positive cells were equivalent in the CCR4+/+ and CCR4-/mice at day 30 after the conidia challenge.

We also examined the expression of F4/80 on the macrophage/monocyte populations in the lung and spleen. Our impetus to explore this cell marker stemmed from earlier studies by Chvatchko et al. (12), who showed that F4/80 expression on peritoneal monocytes and macrophages diminished with time after LPS injection in CCR4-/- mice. The present experiment confirmed this earlier observation, in that markedly fewer macrophages that were positive for F4/80 expression were detected in both the spleen and lung samples from CCR4-/- mice at day 30 after conidia compared with wild-type group. F4/80 has been used as a surface marker for macrophages, but it may more accurately reflect the phagocytic capabilities and/or activation state of these cells (46).

\section{Goblet cell hyperplasia and peribronchial fibrosis persisted in sensitized CCR4-/- mice}

Another feature of an intrapulmonary conidia challenge in A. fumigatus-sensitized mice is an increase in goblet cell hyperplasia and peribronchial fibrosis, which are signs of chronic inflammation (20). PAS staining highlights the presence of goblet cells in the airways of CCR4+/+ mice at days 3 (Fig. 12A), 7 (Fig. 12C), and 30 (Fig. 12E) after the conidia challenge. Similar levels of goblet cell staining were detected in the airways of CCR4-/- mice at the same time points (Fig. 12B, $\underline{D}, \underline{F}$ ). Increased collagen deposition and peribronchial fibrosis can be quantified by the Sircol Collagen Assay (Fig. 13). No differences were noted in the level of collagen present in whole lung samples from CCR4-deficient mice and controls at days 3, 7, or 30. This fact was reiterated via Masson trichrome staining, which revealed no significant differences in peribronchial fibrosis between the two groups of mice (data not shown). It is noteworthy that the extent of peribronchial fibrosis observed in the CCR4+/+ and CCR4-/- mice was markedly inferior to that previously observed in other studies with this model $(20,21)$. This difference presumably reflects the fact that CCR4+/+ and CCR4-/- mice were on a C57BL/6 genetic background, and we have previously observed that C57BL/6 mice develop little peribronchial fibrosis in the context of chronic fungal asthma (unpublished observations).

\section{DISCUSSION}

The present study demonstrated a unique role for CCR4 in the modulation of both innate and acquired immune events during the course of allergic airway disease induced by the fungus $A$. fumigatus. A. fumigatus-sensitized CCR4-/- mice eliminated A. fumigatus spores from their airways by day 7 after the conidia challenge, whereas fungal spores persisted in the lungs of $A$. fumigatus-sensitized CCR4+/+ mice for the 30-day duration of this study. The aggressive, early antifungal response in CCR4-/- mice was associated with increased neutrophil recruitment and activation as well as with markedly increased macrophage numbers in the BAL. In addition, the role of CCR4 in the acquired immune response toward Aspergillus was highlighted by the observation that many of the Th2 cytokine-dependent features of this model including serum $\operatorname{IgE}, \operatorname{IgG1}$, airway hyperresponsiveness, and airway eosinophilia either did not persist or failed to appear in the absence of CCR4. 
Although the A. fumigatus model of fungal asthma has been studied primarily to determine the effects of the acquired immune response to Aspergillus, this study also revealed putative functions of CCR4 in the innate immune response against this fungus. Highlighting the early inherent immune response to fungus in the lung, activation of neutrophils and macrophages is the first line of defense against $A$. fumigatus conidia $(27,47)$. Defects in the ability of either cell type to phagocytose and kill A. fumigatus conidia result in severe invasive lung disease and mortality (48). Although the increased prevalence and activation of both neutrophils and macrophages in the lungs of CCR4-/- mice presumably account for the rapid clearance of conidia from the airways of these mice, the regulatory role that CCR4 exerts in the recruitment and/or activation of neutrophils is not apparent from the present study. Indeed, there is no evidence to date that CCR4 ligands modulate neutrophil function (i.e., MPO release), although a recent study showed that circulating human neutrophils express mRNA for this CC chemokine receptor (49). Further evidence that the absence of CCR4 modulated the activation state of monocyte/macrophage populations in the airways and spleen came from our examination of F4/80 expression on these cells from both groups of mice at day 30 after the conidia challenge. F4/80, a macrophage surface glycoprotein, has commonly been used as a cell identifier, although more recently it has been implicated as an activation marker in monocytes and macrophages, important for cell-to-cell interactions and phagocytosis by these cells $(46,50)$. The markedly decreased F4/80 expression by monocytes/macrophages at day 30 after conidia challenge in CCR4-/- mice (despite the presence of increased numbers of these cells as determined by flow cytometry and BAL counts) suggests that this population may be responsible for the efficient clearance of the fungus seen in these mice (50)." These findings coincide with earlier observations that F4/80 expression by peritoneal macrophages was markedly reduced in CCR4-/mice after LPS-induced sepsis when compared with initial time points (12). Clearly, additional studies are required with both A. fumigatus-sensitized mice and nonsensitized mice to further explore and define the role for CCR4 in the innate immune response by lung macrophages directed against Aspergillus.

Eosinophils are not known to express CCR4, although one of the major ligands of CCR4, CCL22, exhibits potent eosinophil chemoattraction, which suggests that CCL22 may exert its effects independently of CCR4 through some as yet unidentified chemokine receptor $(51,52)$. Immunoneutralization of CCL22 has been shown to significantly reduce eosinophilia as well as airway hyperresponsiveness in an extended (21-day) OVA allergy model (17), although a shorter 5-day OVA challenge in CCR4-/- mice revealed no significant affects on either parameter when compared with results for wild-type littermates (12). As previously reported, CCR4-/- mice express very low levels of CCL22 (12). For the present study, we postulate that the marked reduction in CCL22 levels in CCR4-/- mice contributes to the paucity of eosinophils around the airways and the diminished numbers of eosinophils in the BAL.

The selective expression of CCR4 by Th2 cells suggests that targeting this chemokine receptor may significantly affect the recruitment and persistence of Th2 cells around asthmatic airways $(19,53)$. Effector Th2 cells have been shown to be modulated by both the CCR3/CCL11 (eotaxin) and CCR4/CCL22 pathways acutely, but a progressive increase in the numbers of CCR4-positive cells around the airways of mice chronically challenged with OVA results in the predominance of the CCR4/MDC axis in the long-term recruitment of Th2 cells (54). In our study at day 3 after conidia challenge, CCR4-/- mice had significantly higher levels of Th2 
cytokines than did their wild-type counterparts; however, levels of Th2 cytokines such as IL-4, IL-5, and IL-13 were significantly decreased in the lungs of CCR4-/- mice at day 30 after conidia challenge. Th2 cells can develop normally in CCR4-/- mice (12), but it was surprising, in light of previous reports on the ability of CCR 4 ligands to regulate the recruitment of Th2 cells, that in vivo $T$ cell recruitment did not seem to be affected in the CCR4-/- mice at any time after the conidia challenge. However, in view of the fact that a relatively small proportion of the total $\mathrm{T}$ cell population is composed of Aspergillus antigen-specific Th2 cells, any overall changes in Th2 cell recruitment may have been missed in our flow cytometric experiment. At present, the significant decrease in Th2 cytokine levels in the lungs of CCR4-/- mice suggests that fewer Th2 cells are making to the airways of these mice compared with CCR4+/+ mice.

Given that our previous studies demonstrated that eosinophils and $\mathrm{T}$ cells are major contributors to the airway hyperresponsiveness associated with acute Aspergillus-induced allergic airway disease $(55,56)$ and chronic fungal asthma $(22,26)$, it is conceivable that the paucity of eosinophils and $\mathrm{T}$ cells around the airway contributed, in part, to the changes in airway hyperresponsiveness in CCR4-/- mice. However, we also previously observed that recruited neutrophils appear to modulate the airway hyperresponsiveness during the first week after the administration of conidia into A. fumigatus-sensitized mice (57). CCR4-/- mice exhibited markedly higher numbers of activated neutrophils in their airways compared with their wild-type counterparts, and it is possible that these cells contributed to the airway hyperresponsiveness observed in these mice at days 3 and 7 after the conidia challenge. Regardless of the leukocyte population(s) contributing to the overall changes in airway physiology, our findings are a major departure from previous studies by Chvatchko et al. (12), who showed no difference in airway responses to methacholine between CCR4-/- and CCR4+/+ mice during acute OVA-induced airway inflammation. Our findings are more in keeping with those of Gonzalo and colleagues (17), who showed that the immunoneutralization of CCL22 during acute OVA-induced airway inflammation markedly reduced airway eosinophilia and airway hyperreactivity. However, in our present study, the major deficit in airway hyperreactivity in CCR4-/- mice was apparent only at day 30 after conidia challenge, when the whole lung levels of $\mathrm{Th} 2$ cytokines were significantly lower in the CCR4-/- group versus the control group. The latter observation also differs, in part, from the study of Chvatchko et al. (12), who concluded that the CCR4 deletion does not impair the development of the Th2-mediated response. In principle, our findings agree with this result, because we observed that CCR4-/- mice exhibited a robust pulmonary Th2 cytokine response at day 3 after conidia challenge. Nevertheless, our findings illustrate that the presence of CCR4 is necessary for the maintenance of the Th2-mediated response associated with Aspergillus-induced lung disease. Studies are ongoing to more fully characterize the mechanism through which CCR4 maintains allergic airway disease.

Goblet cell hyperplasia and mucus hypersecretion are common characteristics of asthma and allergic lung disease. Despite the significant decrease in Th2 cytokine levels at day 30, goblet cell hyperplasia was not attenuated in CCR4-/- mice at any time after the conidia challenge. As the majority of the other Th2-associated features of this model were attenuated or abolished, this observation was unexpected. One explanation for the goblet cell hyperplasia in the absence of CCR4 may stem from the markedly augmented lung neutrophil recruitment and activation in CCR4-/- mice during the acute phase (i.e., days 3 and 7) of the chronic fungal asthma response. Results from previous studies suggested that neutrophilia contributes to increased mucin 
expression and goblet cell degranulation $(58,59)$. In addition, enhanced numbers of neutrophils in the airways contribute to goblet cell activation in patients with chronic obstructive pulmonary disease (60), apparently via the action of neutrophil elastase (61). Finally, neutrophils have been implicated in goblet cell hyperplasia during OVA-induced allergic airway disease in guinea pigs (62).

Another feature of chronic airway remodeling, peribronchial fibrosis, involves the production and deposition around the airways of a variety of extracellular matrix proteins such as collagen. The peribronchial fibrosis evident at day 30 was similar in both CCR4+/+ and CCR4-/- groups. Again, this airway-remodeling feature may reflect the dichotomy between the Th2 cytokine levels during the acute and chronic (i.e., day 30) phases of this model. Although profibrotic IL4, IL-5, and IL-13 levels were significantly reduced by day 30 after conidia challenge in CCR4-/mice, IL-4 and IL-5 levels were significantly elevated at day 3 after the conidia challenge. This early increase in the levels of these cytokines may have provided the stimulus that set in motion fibrotic events that were histologically manifest several days later in this model. Recapitulating these events in vitro has been difficult, but it has been shown that cultured human airway smooth muscle cells from normal lung specimens exposed to serum from atopic patients triggers extracellular matrix protein production by these cells many hours later (63). In this manner, the phenotypes of resident airway cells, including the bronchial epithelium, airway smooth muscle cells, and peribronchial fibroblasts, may be activated by factors in their environment early in the course of disease, thereby setting in motion the events that become evident histologically during the later stages of chronic fungal asthma. This paradigm has important implications in the treatment of chronic aspects of fungus-induced asthma.

In summary, the present study demonstrates that a CCR4 gene deficiency in mice markedly changes the innate and acquired immune features of a chronic fungal allergic disease model precipitated by challenge with live A. fumigatus conidia. Although attenuating or reversing chronic remodeling features of fungal asthma may require another therapeutic strategy, overall, CCR4 appears to be an attractive target during the course of chronic fungal asthma, given that its absence leads to a rapid clearance of fungal elements and the attenuation of many of the Th2 cytokine-associated features.

\section{ACKNOWLEDGMENTS}

This study was supported by the National Institutes of Health.

\section{REFERENCES}

1. Imai, T., Chantry, D., Raport, C. J., Wood, C. L., Nishimura, M., Godiska, R., Yoshie, O., and Gray, P. W. (1998) Macrophage-derived chemokine is a functional ligand for the CC chemokine receptor 4. J Biol Chem 273, 1764-1768

2. Chantry, D., Romagnani, P., Raport, C. J., Wood, C. L., Epp, A., Romagnani, S., and Gray, P. W. (1999) Macrophage-derived chemokine is localized to thymic medullary epithelial cells and is a chemoattractant for $\mathrm{CD}^{+}, \mathrm{CD} 4^{+}, \mathrm{CD} 8^{\text {low }}$ thymocytes. Blood 94, $1890-1898$ 
3. Vestergaard, C., Yoneyama, H., Murai, M., Nakamura, K., Tamaki, K., Terashima, Y., Imai, T., Yoshie, O., Irimura, T., Mizutani, H., and Matsushima, K. (1999) Overproduction of Th2-specific chemokines in $\mathrm{NC} / \mathrm{Nga}$ mice exhibiting atopic dermatitis-like lesions. J Clin Invest 104, 1097-1105

4. Campbell, J. J., Haraldsen, G., Pan, J., Rottman, J., Qin, S., Ponath, P., Andrew, D. P., Warnke, R., Ruffing, N., Kassam, N., Wu, L., and Butcher, E. C. (1999) The chemokine receptor CCR4 in vascular recognition by cutaneous but not intestinal memory $\mathrm{T}$ cells. Nature (London) 400, 776-780

5. Gutierrez-Ramos, J. C., Lloyd, C., Kapsenberg, M. L., Gonzalo, J. A., and Coyle, A. J. (2000) Non-redundant functional groups of chemokines operate in a coordinate manner during the inflammatory response in the lung. Immunol Rev 177, 31-42

6. Godiska, R., Chantry, D., Raport, C. J., Sozzani, S., Allavena, P., Leviten, D., Mantovani, A., and Gray, P. W. (1997) Human macrophage-derived chemokine (MDC), a novel chemoattractant for monocytes, monocyte-derived dendritic cells, and natural killer cells. $J$ Exp Med 185, 1595-1604

7. Berin, M. C., Eckmann, L., Broide, D. H., and Kagnoff, M. F. (2001) Regulated production of the $\mathrm{T}$ helper 2-type T-cell chemoattractant TARC by human bronchial epithelial cells in vitro and in human lung xenografts. Am J Respir Cell Mol Biol 24, 382389

8. Power, C. A., Meyer, A., Nemeth, K., Bacon, K. B., Hoogewerf, A. J., Proudfoot, A. E., and Wells, T. N. (1995) Molecular cloning and functional expression of a novel CC chemokine receptor cDNA from a human basophilic cell line. J Biol Chem 270, 1949519500

9. Imai, T., Baba, M., Nishimura, M., Kakizaki, M., Takagi, S., and Yoshie, O. (1997) The $\mathrm{T}$ cell directed $\mathrm{CC}$ chemokine TARC is a highly specific ligand for $\mathrm{CC}$ chemokine receptor 4. J Biol Chem 272, 15036-15042

10. Mantovani, A., Gray, P. A., Van Damme, J., and Sozzani, S. (2000) Macrophage-derived chemokine (MDC). J Leukoc Biol 68, 400-404

11. Rodenburg, R. J., Brinkhuis, R. F., Peek, R., Westphal, J. R., Van Den Hoogen, F. H., van Venrooij, W. J., and van de Putte, L. B. (1998) Expression of macrophage-derived chemokine (MDC) mRNA in macrophages is enhanced by interleukin-1 $\beta$, tumor necrosis factor $\alpha$, and lipopolysaccharide. J Leukoc Biol 63, 606-611

12. Chvatchko, Y., Hoogewerf, A. J., Meyer, A., Alouani, S., Juillard, P., Buser, R., Conquet, F., Proudfoot, A. E., Wells, T. N., and Power, C. A. (2000) A key role for CC chemokine receptor 4 in lipopolysaccharide-induced endotoxic shock. J Exp Med 191, 1755-1764 
13. Wu, M., Fang, H., and Hwang, S. T. (2001) Cutting edge: CCR4 mediates antigenprimed T cell binding to activated dendritic cells. J Immunol 167, 4791-4795

14. Matsukawa, A., Hogaboam, C. M., Lukacs, N. W., and Kunkel, S. L. (2000) Chemokines and innate immunity. Rev Immunogenet 2, 339-358

15. Lukacs, N. W., Oliveira, S. H., and Hogaboam, C. M. (1999) Chemokines and asthma: redundancy of function or a coordinated effort? J Clin Invest 104, 995-999

16. Matsukawa, A., Hogaboam, C. M., Lukacs, N. W., Lincoln, P. M., Evanoff, H. L., and Kunkel, S. L. (2000) Pivotal role of the CC chemokine, macrophage-derived chemokine, in the innate immune response. J Immunol 164, 5362-5368

17. Gonzalo, J. A., Pan, Y., Lloyd, C. M., Jia, G. Q., Yu, G., Dussault, B., Powers, C. A., Proudfoot, A. E., Coyle, A. J., Gearing, D., and Gutierrez-Ramos, J. C. (1999) Mouse monocyte-derived chemokine is involved in airway hyperreactivity and lung inflammation. J Immunol 163, 403-411

18. Kawasaki, S., Takizawa, H., Yoneyama, H., Nakayama, T., Fujisawa, R., Izumizaki, M., Imai, T., Yoshie, O., Homma, I., Yamamoto, K., and Matsushima, K. (2001) Intervention of thymus and activation-regulated chemokine attenuates the development of allergic airway inflammation and hyperresponsiveness in mice. J Immunol 166, 2055-2062

19. Panina-Bordignon, P., Papi, A., Mariani, M., Di Lucia, P., Casoni, G., Bellettato, C., Buonsanti, C., Miotto, D., Mapp, C., Villa, A., Arrigoni, G., Fabbri, L. M., and Sinigaglia, F. (2001) The C-C chemokine receptors CCR4 and CCR8 identify airway T cells of allergen-challenged atopic asthmatics. J Clin Invest 107, 1357-1364

20. Hogaboam, C. M., Blease, K., Mehrad, B., Steinhauser, M. L., Standiford, T. J., Kunkel, S. L., and Lukacs, N. W. (2000) Chronic airway hyperreactivity, goblet cell hyperplasia, and peribronchial fibrosis during allergic airway disease induced by Aspergillus fumigatus. Am. J. Pathol. 156, 723-732

21. Blease, K., Mehrad, B., Standiford, T. J., Lukacs, N. W., Gosling, J., Boring, L., Charo, I. F., Kunkel, S. L., and Hogaboam, C. M. (2000) Enhanced pulmonary allergic responses to Aspergillus in CCR2-/- mice. J Immunol 165, 2603-2611

22. Blease, K., Mehrad, B., Lukacs, N. W., Kunkel, S. L., Standiford, T. J., and Hogaboam, C. M. (2001) Antifungal and airway remodeling roles for murine monocyte chemoattractant protein-1/CCL2 during pulmonary exposure to Asperigillus fumigatus conidia. J Immunol 166, 1832-1842

23. Blease, K., Mehrad, B., Standiford, T. J., Lukacs, N. W., Kunkel, S. L., Chensue, S. W., Lu, B., Gerard, C. J., and Hogaboam, C. M. (2000) Airway remodeling is absent in CCR1-/- mice during chronic fungal allergic airway disease. J Immunol 165, 1564-1572 
24. Lukacs, N. W., Hogaboam, C., Chensue, S. W., Blease, K., and Kunkel, S. L. (2001) Type 1/type 2 cytokine paradigm and the progression of pulmonary fibrosis. Chest 120, $5 \mathrm{~S}-8 \mathrm{~S}$

25. Campbell, E. M., Charo, I. F., Kunkel, S. L., Strieter, R. M., Boring, L., Gosling, J., and Lukacs, N. W. (1999) Monocyte chemoattractant protein-1 mediates cockroach allergeninduced bronchial hyperreactivity in normal but not CCR2-/- mice: the role of mast cells. J Immunol 163, 2160-2167

26. Blease, K., Jakubzick, C., Westwick, J., Lukacs, N., Kunkel, S. L., and Hogaboam, C. M. (2001) Therapeutic effect of IL-13 immunoneutralization during chronic experimental fungal asthma. J Immunol 166, 5219-5224

27. Roilides, E., Holmes, A., Blake, C., Venzon, D., Pizzo, P. A., and Walsh, T. J. (1994) Antifungal activity of elutriated human monocytes against Aspergillus fumigatus hyphae: enhancement by granulocyte-macrophage colony-stimulating factor and interferongamma. J Infect Dis 170, 894-899

28. Waldorf, A. R. (1989) Pulmonary defense mechanisms against opportunistic fungal pathogens. Immunol Ser 47, 243-271

29. Nocker, R. E., Schoonbrood, D. F., van de Graaf, E. A., Hack, C. E., Lutter, R., Jansen, H. M., and Out, T. A. (1996) Interleukin-8 in airway inflammation in patients with asthma and chronic obstructive pulmonary disease. Int Arch Allergy Immunol 109, 183191

30. Mehrad, B., Strieter, R. M., and Standiford, T. J. (1999) Role of TNF- $\alpha$ in pulmonary host defense in murine invasive aspergillosis. J Immunol 162, 1633-1640

31. Grunig, G., Corry, D. B., Leach, M. W., Seymour, B. W., Kurup, V. P., and Rennick, D. M. (1997) Interleukin-10 is a natural suppressor of cytokine production and inflammation in a murine model of allergic bronchopulmonary aspergillosis. J Exp Med 185, 10891099

32. Roilides, E., Dimitriadou, A., Kadiltsoglou, I., Sein, T., Karpouzas, J., Pizzo, P. A., and Walsh, T. J. (1997) IL-10 exerts suppressive and enhancing effects on antifungal activity of mononuclear phagocytes against Aspergillus fumigatus. J Immunol 158, 322-329

33. Clemons, K. V., Grunig, G., Sobel, R. A., Mirels, L. F., Rennick, D. M., and Stevens, D. A. (2000) Role of IL-10 in invasive aspergillosis: increased resistance of IL-10 gene knockout mice to lethal systemic aspergillosis. Clin Exp Immunol 122, 186-191

34. Del Sero, G., Mencacci, A., Cenci, E., d'Ostiani, C. F., Montagnoli, C., Bacci, A., Mosci, P., Kopf, M., and Romani, L. (1999) Antifungal type 1 responses are upregulated in IL10-deficient mice. Microbes Infect 1, 1169-1180 
35. Murali, P. S., Kurup, V. P., Bansal, N. K., Fink, J. N., and Greenberger, P. A. (1998) IgE down regulation and cytokine induction by Aspergillus antigens in human allergic bronchopulmonary aspergillosis. J Lab Clin Med 131, 228-235

36. Cockrill, B. A., and Hales, C. A. (1999) Allergic bronchopulmonary aspergillosis. Annu Rev Med 50, 303-316

37. Greenberger, P. A., and Patterson, R. (1987) Allergic bronchopulmonary aspergillosis. Model of bronchopulmonary disease with defined serologic, radiologic, pathologic and clinical findings from asthma to fatal destructive lung disease. Chest 91, 165S-171S

38. Kauffman, H. F., Tomee, J. F., van der Werf, T. S., de Monchy, J. G., and Koeter, G. K. (1995) Review of fungus-induced asthmatic reactions. Am J Respir Crit Care Med 151, 2109-2115

39. Mosmann, T. R., and Coffman, R. L. (1989) TH1 and TH2 cells: different patterns of lymphokine secretion lead to different functional properties. Апnи Rev Immunol 7, 145173

40. Rothenberg, M. E., Petersen, J., Stevens, R. L., Silberstein, D. S., McKenzie, D. T., Austen, K. F., and Owen, W. F. (1989) IL-5-dependent conversion of normodense human eosinophils to the hypodense phenotype uses 3T3 fibroblasts for enhanced viability, accelerated hypodensity, and sustained antibody-dependent cytotoxicity. J Immunol 143, 2311-2316

41. Grunig, G., Warnock, M., Wakil, A. E., Venkayya, R., Brombacher, F., Rennick, D. M., Sheppard, D., Mohrs, M., Donaldson, D. D., Locksley, R. M., and Corry, D. B. (1998) Requirement for IL-13 independently of IL-4 in experimental asthma. Science 282, 22612263

42. Wills-Karp, M., Luyimbazi, J., Xu, X., Schofield, B., Neben, T. Y., Karp, C. L., and Donaldson, D. D. (1998) Interleukin-13: central mediator of allergic asthma. Science 282, 2258-2261

43. Zhu, Z., Homer, R. J., Wang, Z., Chen, Q., Geba, G. P., Wang, J., Zhang, Y., and Elias, J. A. (1999) Pulmonary expression of interleukin-13 causes inflammation, mucus hypersecretion, subepithelial fibrosis, physiologic abnormalities, and eotaxin production. J Clin Invest 103, 779-788

44. Blease, K., Schuh, J., Jakubzick, C., Lukacs, N. W., Kunkel, S. L., Joshi, B. H., Puri, R. K., Kaplan, M. H., and Hogaboam, C. M. (2002) Stat6-deficient mice develop airway hyperresponsiveness and peribronchial fibrosis during chronic fungal asthma. Am J Pathol 160, 481-490 
45. Blease, K., Jakubzick, C., Schuh, J. M., Joshi, B. H., Puri, R. K., and Hogaboam, C. M. (2001) IL-13 fusion cytotoxin ameliorates chronic fungal-induced allergic airway disease in mice. J Immunol 167, 6583-6592

46. Hamerman, J. A., and Aderem, A. (2001) Functional transitions in macrophages during in vivo infection with Mycobacterium bovis bacillus Calmette-Guerin. J Immunol 167, 2227-2233

47. Roilides, E., Katsifa, H., and Walsh, T. J. (1998) Pulmonary host defenses against Aspergillus fumigatus. Res Immunol 149, 454-465

48. Elstad, M. R. (1991) Aspergillosis and lung defenses. Semin Respir Infect 6, 27-36

49. Yousefi, S., Cooper, P. R., Potter, S. L., Mueck, B., and Jarai, G. (2001) Cloning and expression analysis of a novel G-protein-coupled receptor selectively expressed on granulocytes. J Leukoc Biol 69, 1045-1052

50. Warschkau, H., and Kiderlen, A. F. (1999) A monoclonal antibody directed against the murine macrophage surface molecule F4/80 modulates natural immune response to Listeria monocytogenes. J Immunol 163, 3409-3416

51. Bochner, B. S., Bickel, C. A., Taylor, M. L., MacGlashan, D. W., Jr., Gray, P. W., Raport, C. J., and Godiska, R. (1999) Macrophage-derived chemokine induces human eosinophil chemotaxis in a CC chemokine receptor 3- and CC chemokine receptor 4independent manner. J Allergy Clin Immunol 103, 527-532

52. Nagase, H., Kudo, K., Izumi, S., Ohta, K., Kobayashi, N., Yamaguchi, M., Matsushima, K., Morita, Y., Yamamoto, K., and Hirai, K. (2001) Chemokine receptor expression profile of eosinophils at inflamed tissue sites: decreased CCR3 and increased CXCR4 expression by lung eosinophils. J Allergy Clin Immunol 108, 563-569

53. D'Ambrosio, D., Iellem, A., Bonecchi, R., Mazzeo, D., Sozzani, S., Mantovani, A., and Sinigaglia, F. (1998) Selective up-regulation of chemokine receptors CCR4 and CCR8 upon activation of polarized human type 2 Th cells. J Immunol 161, 5111-5115

54. Lloyd, C. M., Delaney, T., Nguyen, T., Tian, J., Martinez, A. C., Coyle, A. J., and Gutierrez-Ramos, J. C. (2000) CC chemokine receptor (CCR)3/eotaxin is followed by CCR4/monocyte-derived chemokine in mediating pulmonary T helper lymphocyte type 2 recruitment after serial antigen challenge in vivo. $J$ Exp Med 191, 265-274

55. Hogaboam, C. M., Gallinat, C. S., Taub, D. D., Strieter, R. M., Kunkel, S. L., and Lukacs, N. W. (1999) Immunomodulatory role of C10 chemokine in a murine model of allergic bronchopulmonary aspergillosis. J Immunol 162, 6071-6079 
56. Schuh, J. M., Blease, K., Kunkel, S. L., and Hogaboam, C. M. (2002) Eotaxin/CCL11 is involved in acute, but not chronic, allergic airway responses to Aspergillus fumigatus. Am J Physiol In press

57. Schuh, J. M., Blease, K., and Hogaboam, C. M. (2002) CXCR2 is necessary for the development and persistence of chronic fungal asthma in mice. $J$ Immunol 168, 14471456

58. Nadel, J. A. (1991) Role of enzymes from inflammatory cells on airway submucosal gland secretion. Respiration 58, 3-5

59. Burgel, P. R., Escudier, E., Coste, A., Dao-Pick, T., Ueki, I. F., Takeyama, K., Shim, J. J., Murr, A. H., and Nadel, J. A. (2000) Relation of epidermal growth factor receptor expression to goblet cell hyperplasia in nasal polyps. J Allergy Clin Immunol 106, 705 712

60. Nadel, J. A. (2000) Role of neutrophil elastase in hypersecretion during COPD exacerbations, and proposed therapies. Chest 117, 386S-389S

61. Nogami, H., Aizawa, H., Matsumoto, K., Nakano, H., Koto, H., Miyazaki, H., Hirose, T., Nishima, S., and Hara, N. (2000) Neutrophil elastase inhibitor, ONO-5046 suppresses ozone-induced airway mucus hypersecretion in guinea pigs. Eur J Pharmacol 390, 197202

62. Agusti, C., Takeyama, K., Cardell, L. O., Ueki, I., Lausier, J., Lou, Y. P., and Nadel, J. A. (1998) Goblet cell degranulation after antigen challenge in sensitized guinea pigs. Role of neutrophils. Am J Respir Crit Care Med 158, 1253-1258

63. Johnson, P. R., Black, J. L., Carlin, S., Ge, Q., and Underwood, P. A. (2000) The production of extracellular matrix proteins by human passively sensitized airway smoothmuscle cells in culture: the effect of beclomethasone. Am J Respir Crit Care Med 162, 2145-2151

64. Campbell, E., Kunkel, S. L., Strieter, R. M., and Lukacs, N. W. (2000) Differential roles of IL-18 in allergic airway disease: induction of eotaxin by resident cell populations exacerbates eosinophil accumulation. J Immunol 164, 1096-1102 
Fig. 1
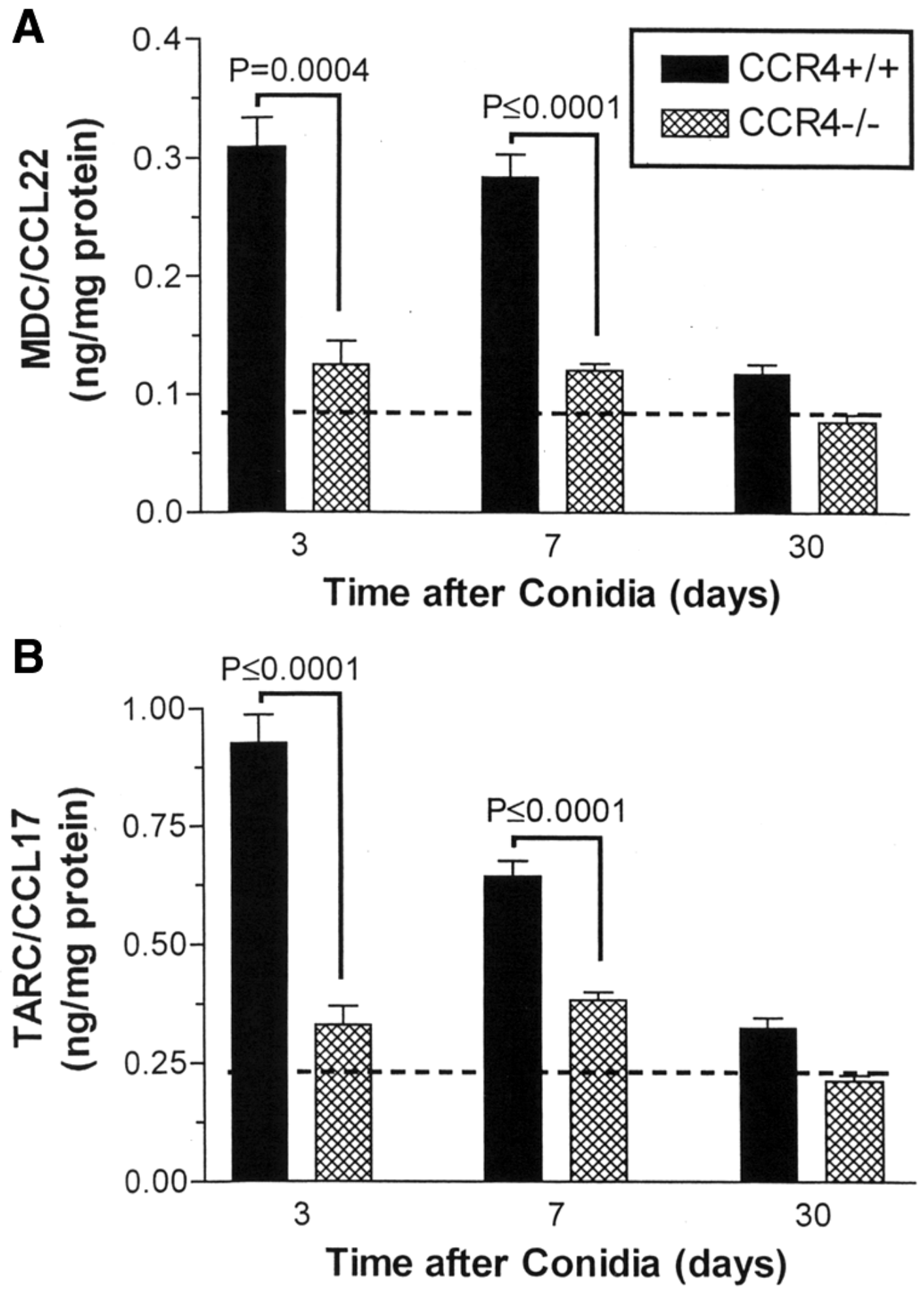

Figure 1. Whole lung MDC/CCL22 (A) and TARC/CCL17 (B) levels in A. fumigatus-sensitized CCR4+/+ and CCR4-/mice at days 3, 7, and 30 after conidia challenge. The dashed lines in both panels indicate the average baseline levels of CCL22 and CCL17 prior to the conidia challenge. No difference in baseline levels of either chemokine was noted between the two groups of mice prior to the conidia challenge. Chemokines were measured by using specific ELISAs. Data represent the mean \pm SE; $n=5-7$ mice/group. 
Fig. 2

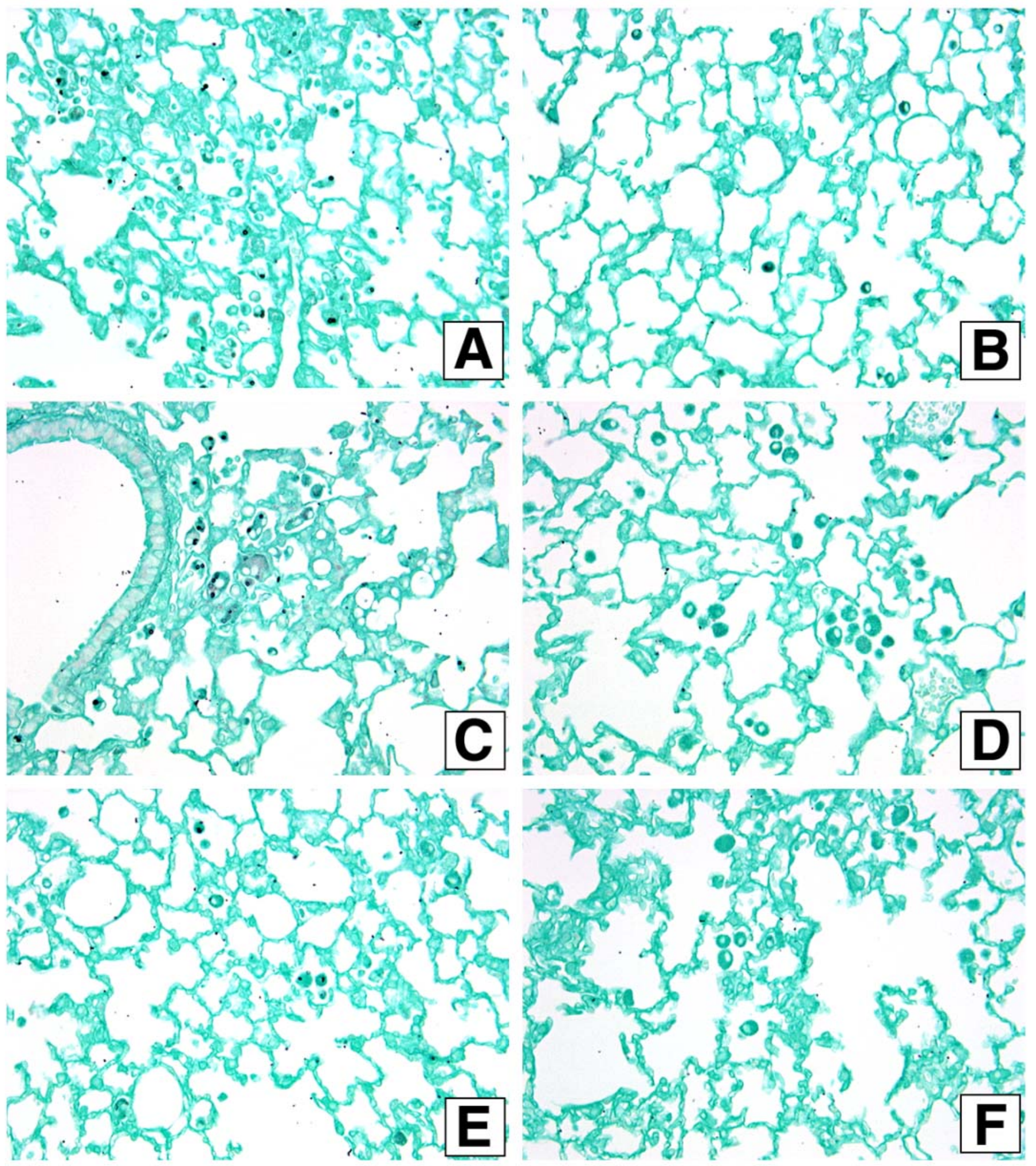

Figure 2. GMS-stained whole lung sections from CCR4+/+ mice (A, C, and $\mathbf{E})$ and CCR4-/- mice (B, D, and $\mathbf{F})$ at days 3 (A and B), 7 (C and D), and 30 (E and F). Fungal material appears black. Original magnification was $200 \times$. 
Fig. 3

Day 3
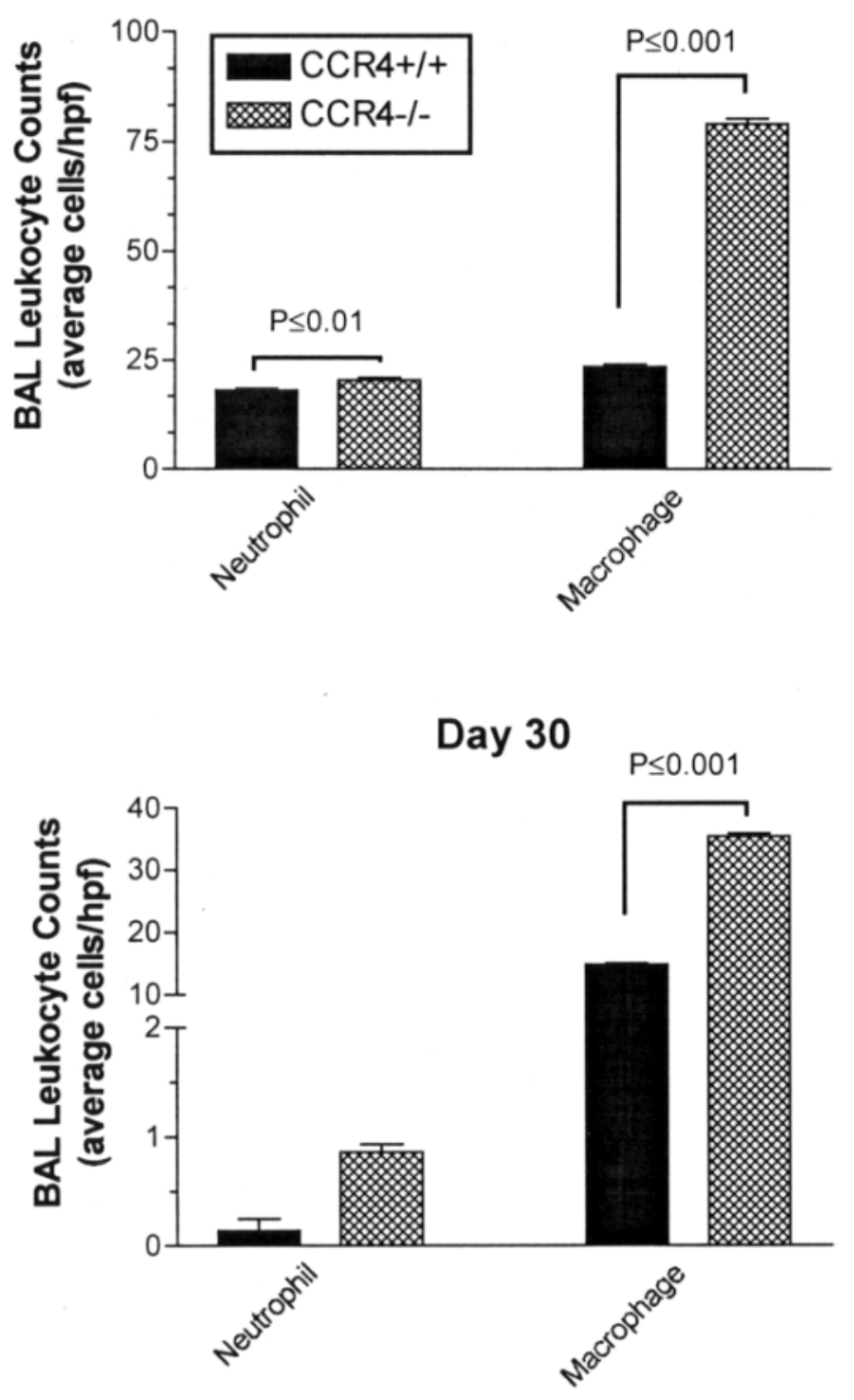

Day 7

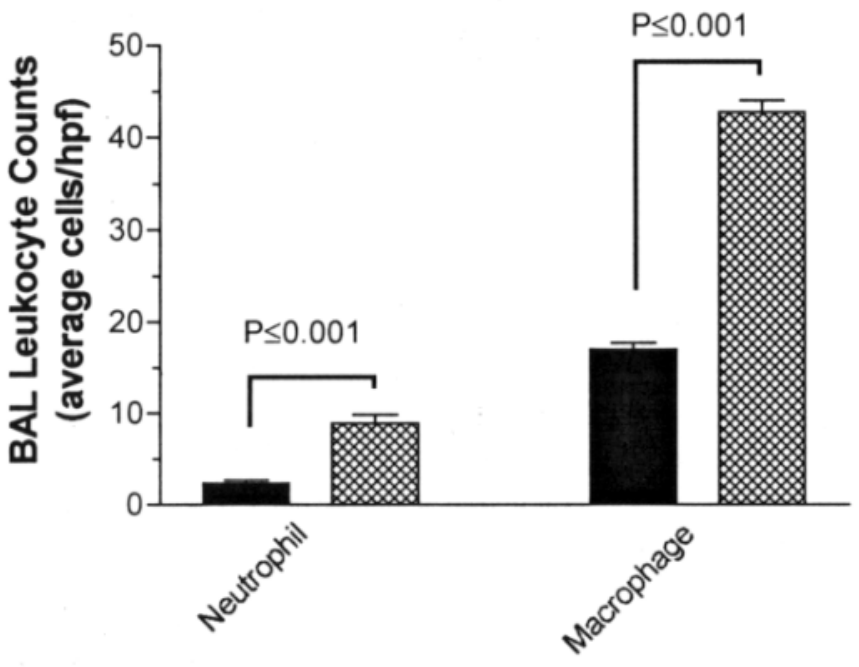

Figure 3. Neutrophil and macrophage counts in BAL samples at days 3, 7, and 30 after conidia challenge in $A$. fumigatus-sensitized CCR4+/+ and CCR4-/- mice. Data are expressed as the mean \pm SE of the average number of cells per HPF. 
Fig. 4

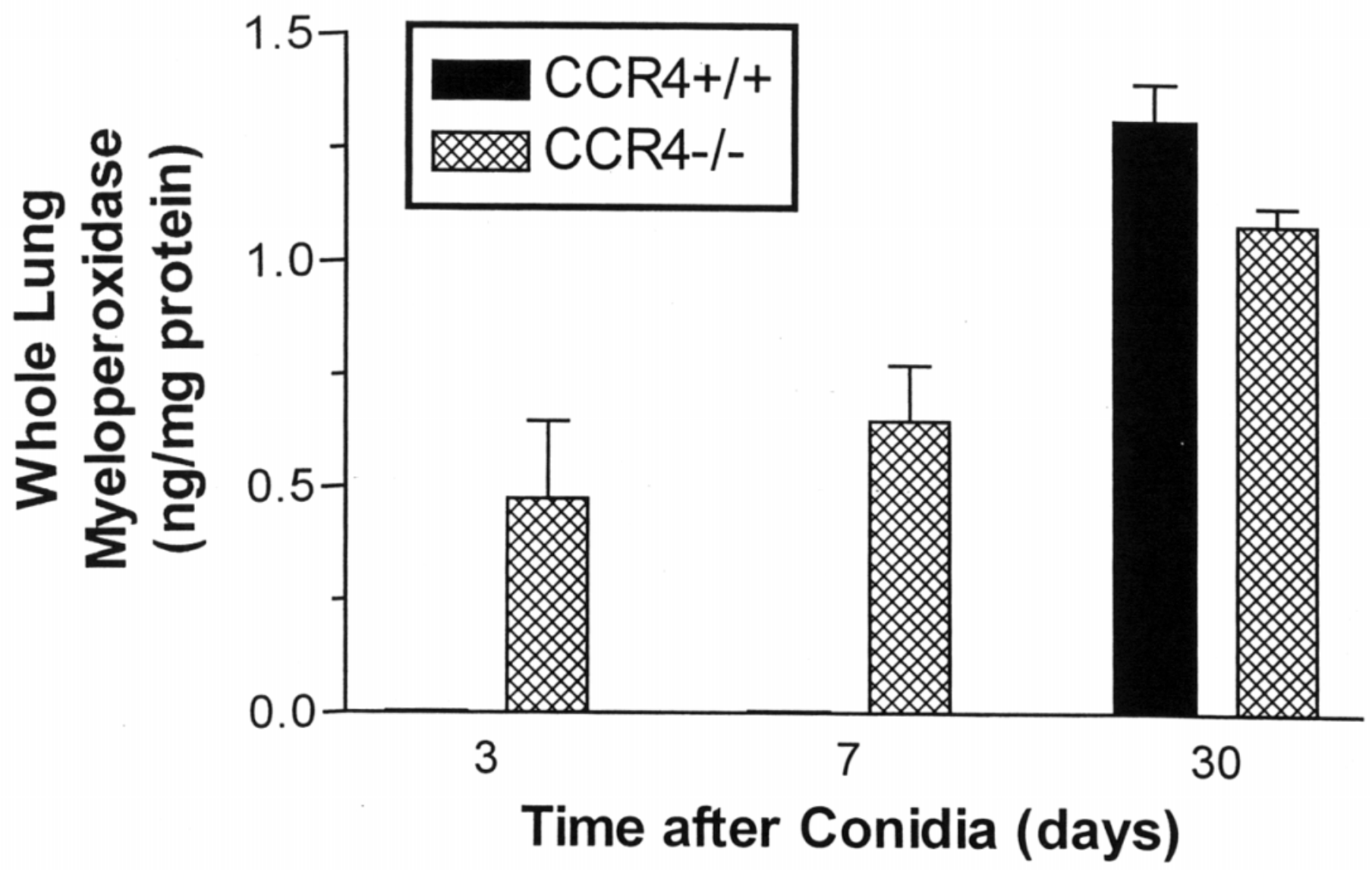

Figure 4. Whole lung MPO levels in A. fumigatus-sensitized CCR4+/+ and CCR4-/- mice at days 3, 7, and 30 after conidia challenge. MPO was measured by using a specific ELISA. MPO levels in whole lung samples from CCR4+/+ mice were below the limits of detection of this assay at days 3 and 7 ( $>50 \mathrm{pg} / \mathrm{mg}$ of protein). Data represent the mean \pm SE; $n=5-7$ mice/group. 
Fig. 5
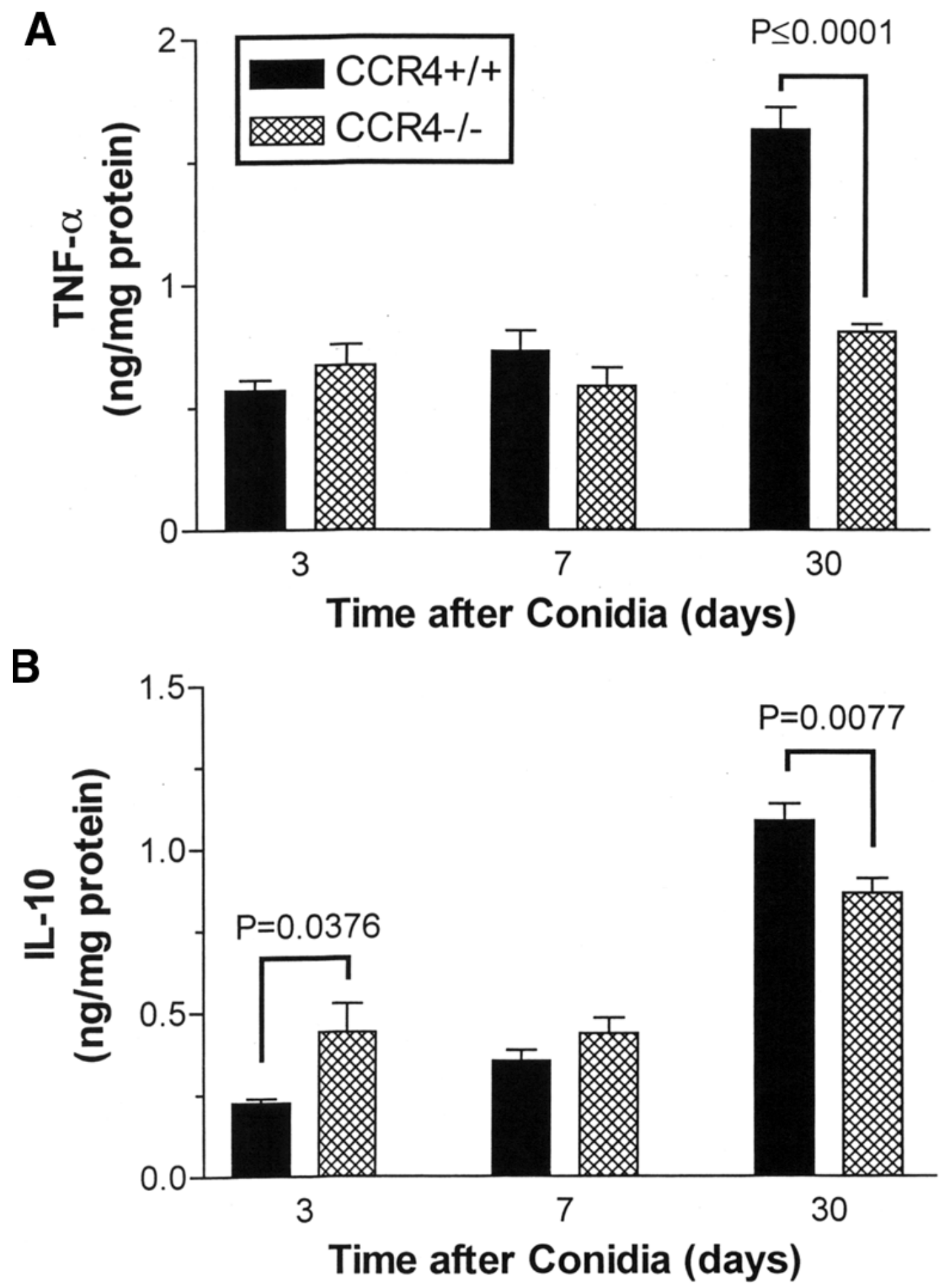

Figure 5. Whole lung levels of TNF- $\alpha$ (A) and IL-10 (B) at days 3, 7, and 30 after conidia challenge in A. fumigatussensitized CCR4+/+ and CCR4-/- mice. Immunoreactive cytokine and chemokine levels were determined by using specific ELISAs as described in Materials and Methods. Values are expressed as the mean \pm SE; $n=5-7$ mice/group. 
Fig. 6
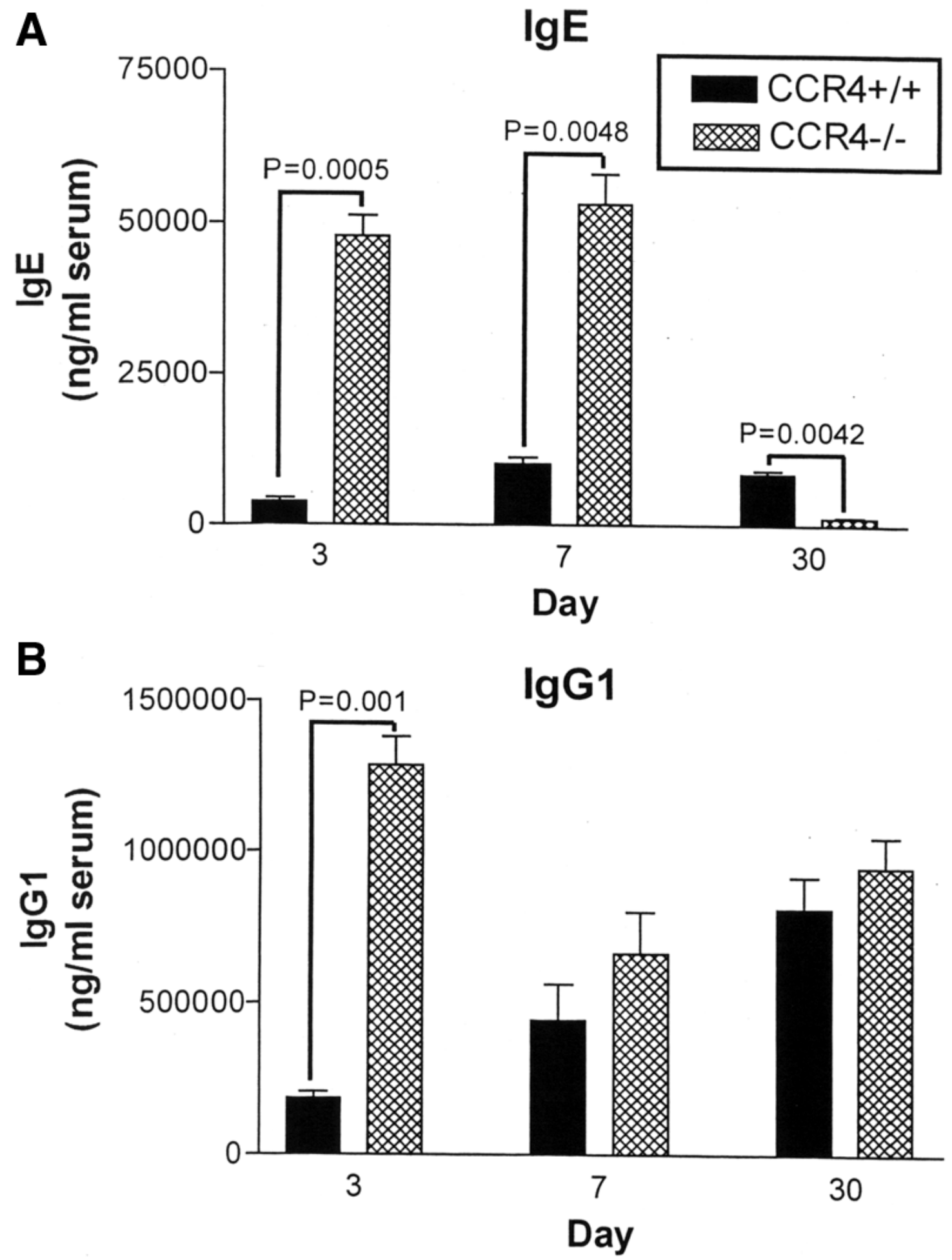

Figure 6. Total serum levels of $\operatorname{IgE}(\mathbf{A})$ and $\operatorname{IgG} 1$ (B) at days 3, 7, and 30 after conidia challenge in A. fumigatussensitized CCR4+/+ and CCR4-/- mice. Total IgE and IgG1 levels were measured by using specific ELISAs as described in Materials and Methods. Data are expressed as the mean \pm SE; $n=5-7$ mice/group. 
Fig. 7

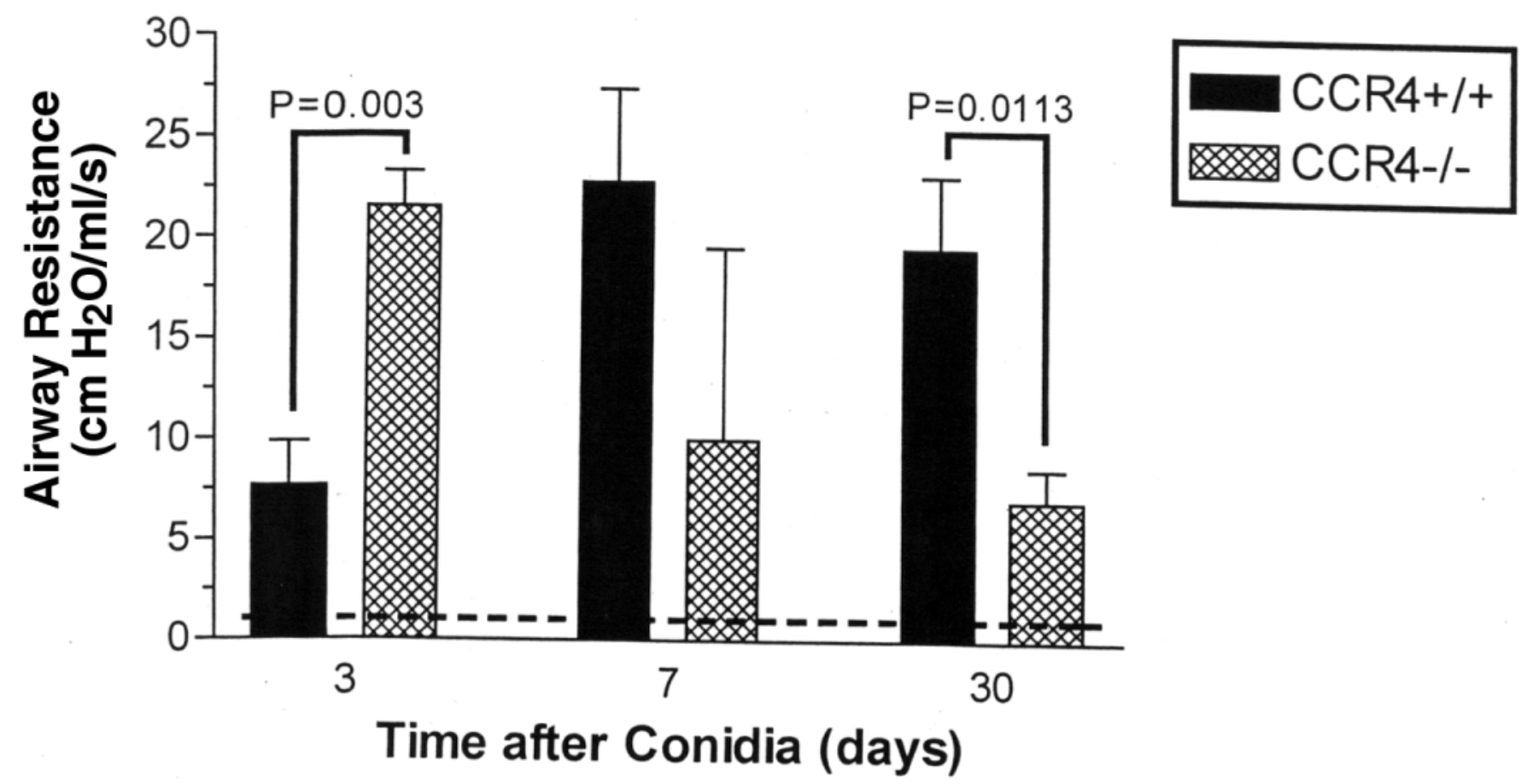

Figure 7. Airway hyperresponsiveness at days 3, 7, and 30 after conidia challenge in A. fumigatus-sensitized CCR4+/+ and CCR4-/- mice. The baseline airway resistance in all groups was similar prior to the methacholine provocation and is indicated for both groups by the dashed line $\left(1.6 \pm 0.5 \mathrm{~cm} \mathrm{H}_{2} \mathrm{O} / \mathrm{ml} / \mathrm{s}\right)$. Peak increases in airway resistance were stimulated by using an intravenous methacholine injection dose of $520 \mu \mathrm{g} / \mathrm{kg}$. This dose caused maximal changes in airway hyperresponsiveness in both groups of mice. Values are expressed as the mean $\pm \mathrm{SE} ; n=5-7$ mice/group. 
Fig. 8
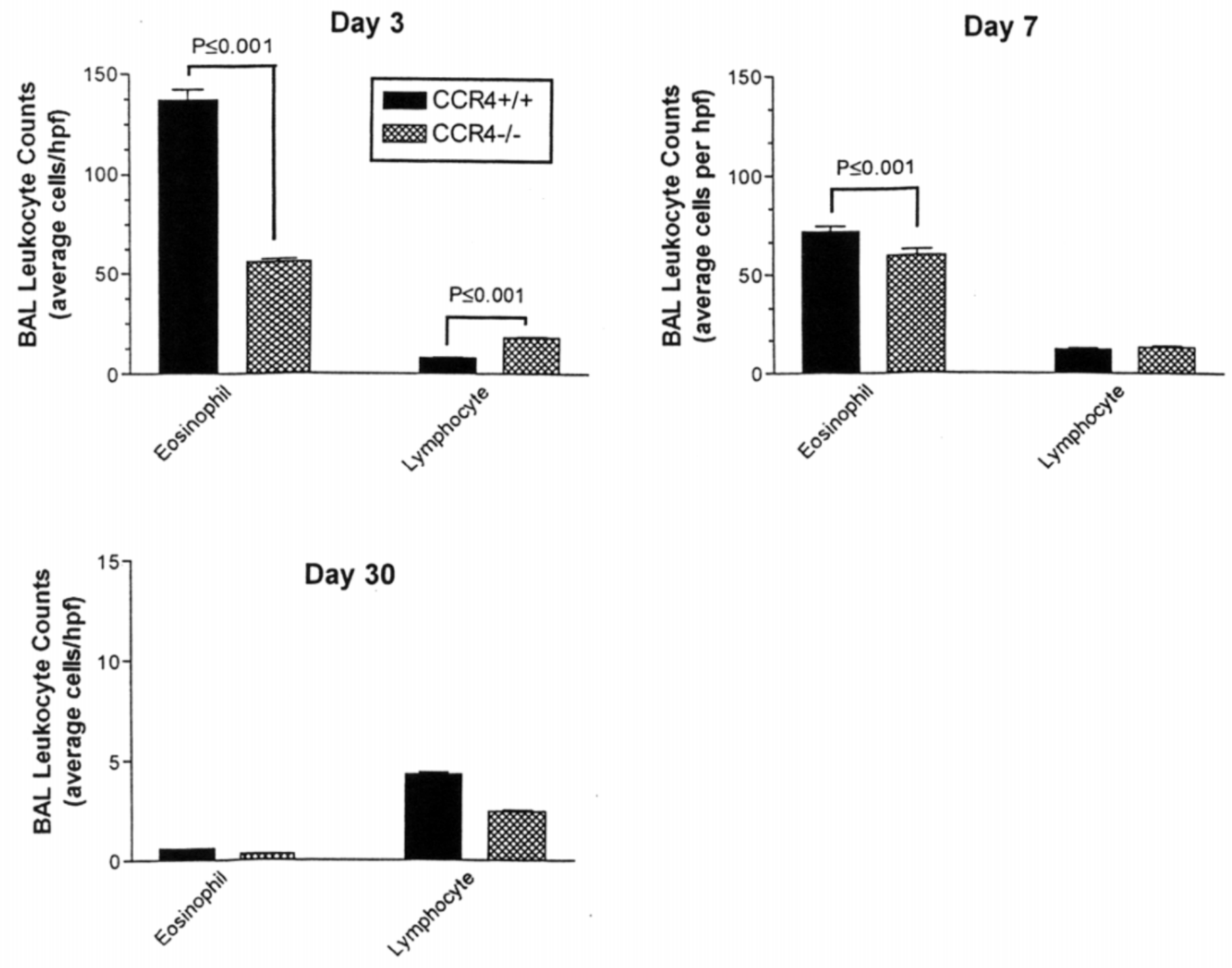

Figure 8. Eosinophil and lymphocyte counts in BAL samples at days 3, 7, and 30 after conidia challenge in A. fumigatussensitized CCR4+/+ and CCR4-/- mice. Data are expressed as the mean \pm SE of cells per HPF. Please note that the scale for day 30 is reduced by 10 -fold. 
Fig. 9

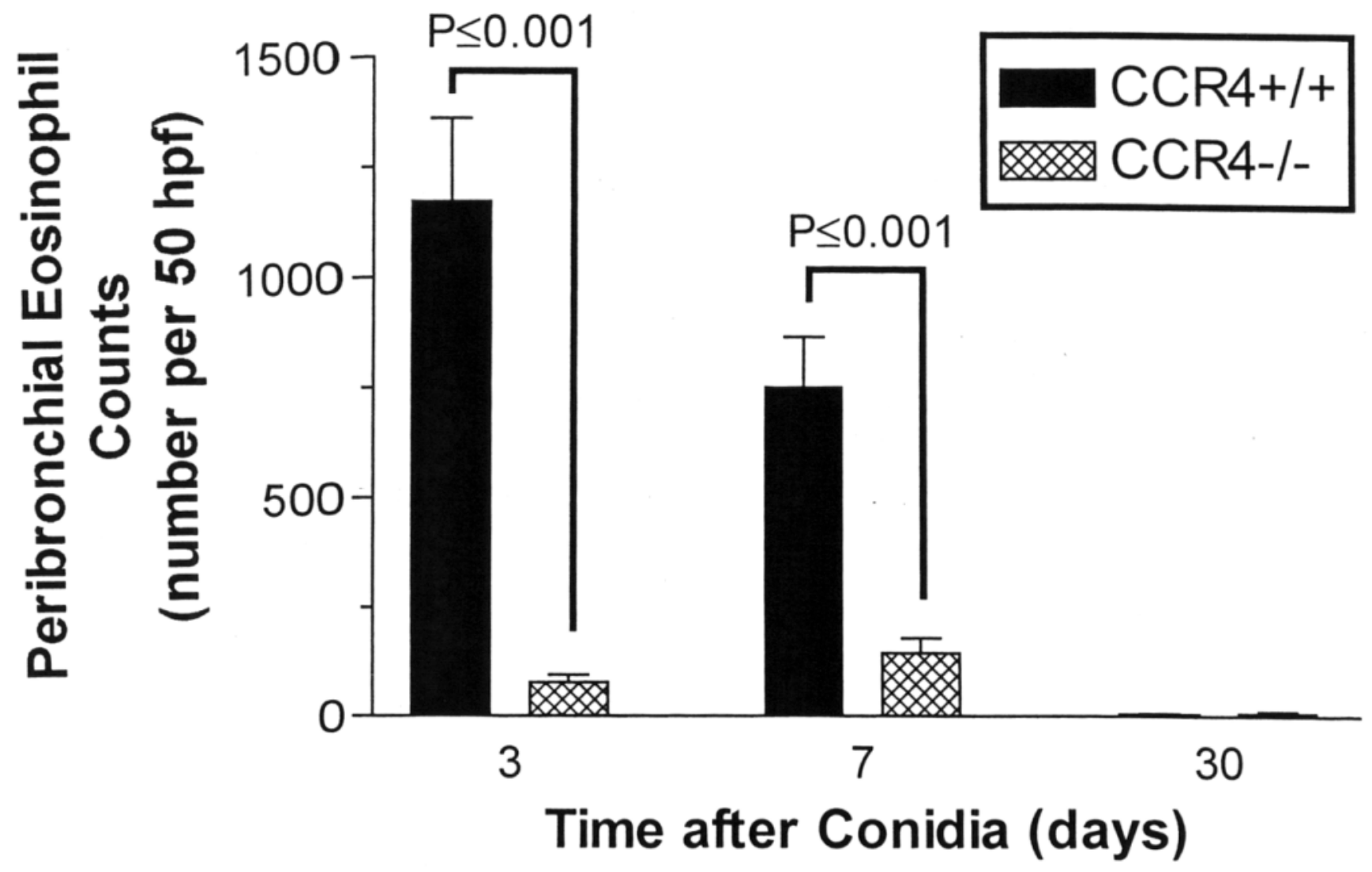

Figure 9. Peribronchial eosinophilia at days 3, 7, and 30 after conidia challenge in A. fumigatus-sensitized CCR4+/+ and CCR4-/- mice. Eosinophils were counted in 100 HPFs per lung using multiple step sections of lung. The eosinophils counted were only in the peribronchial region; this ensured the enumeration of only those eosinophils within or immediately adjacent to an airway (64). Data are expressed as the mean \pm SE of the number of cells per HPF. 
Fig. 10

A

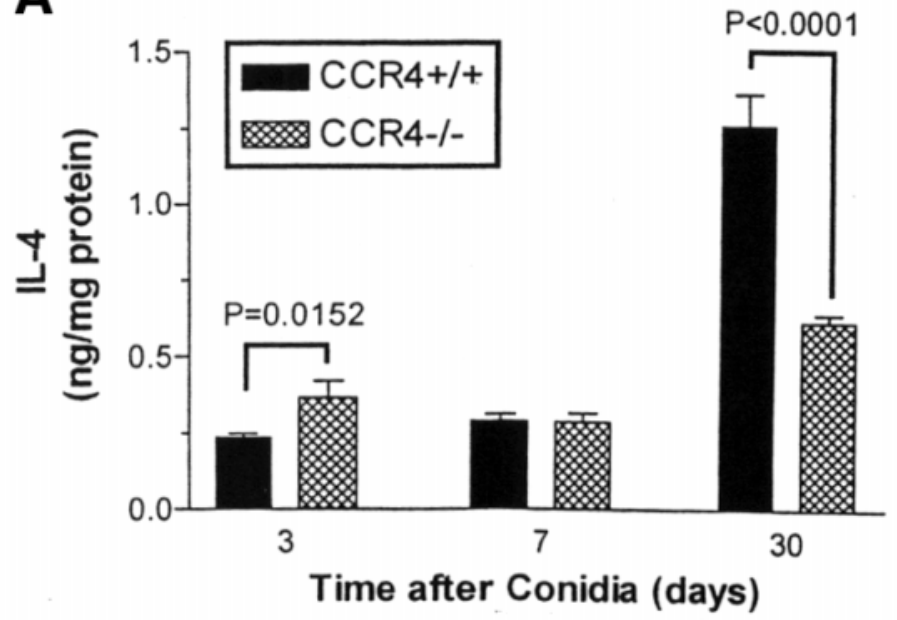

C

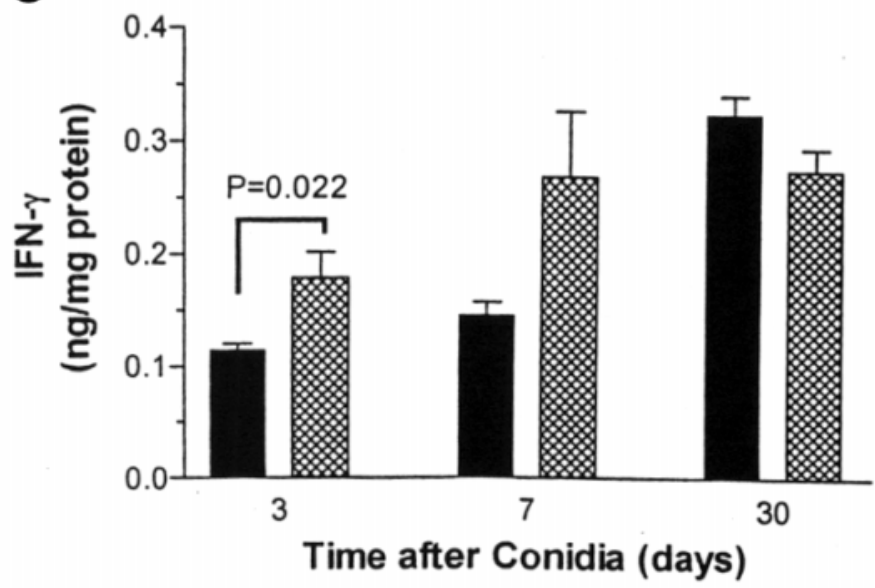

B

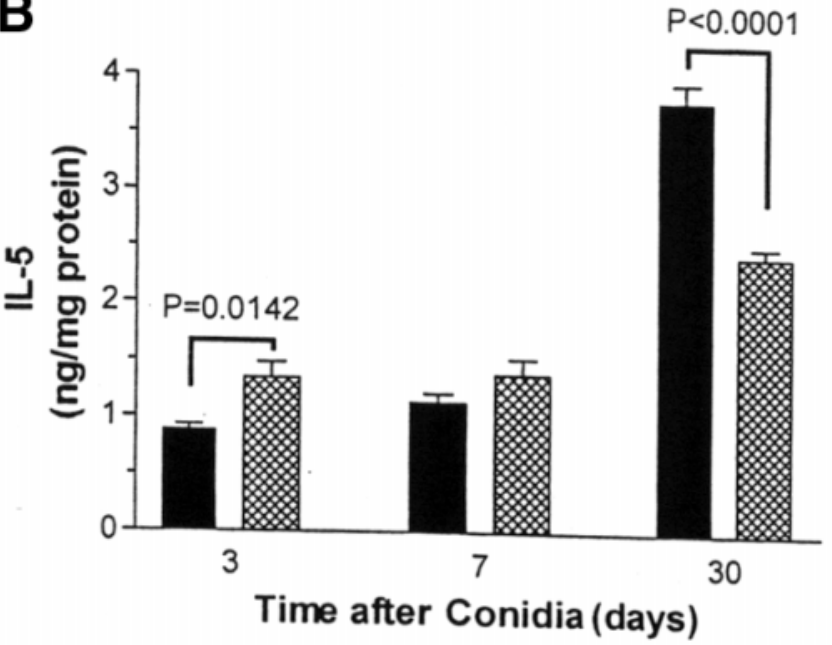

D

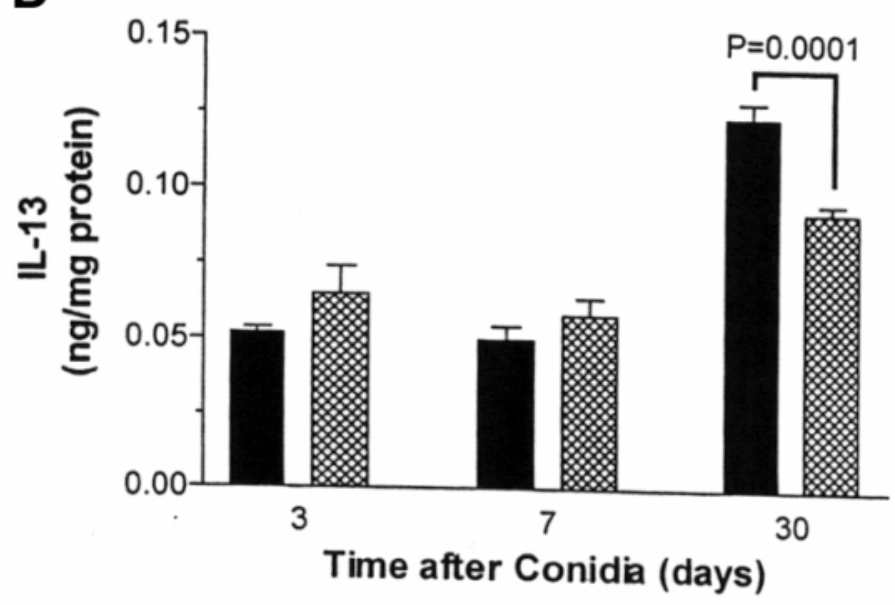

Figure 10. Whole lung levels of IL-4 (A), IL-5 (B), IFN- $\gamma(\mathbf{C})$, and IL-13 (D) at days 3, 7, and 30 after conidia challenge in A. fumigatus-sensitized CCR4+/+ and CCR4-/- mice. Immunoreactive cytokine and chemokine levels were determined by using specific ELISAs as described in Materials and Methods. Values are expressed as the mean \pm SE; $n=5-7$ mice/group. 
Fig. 11

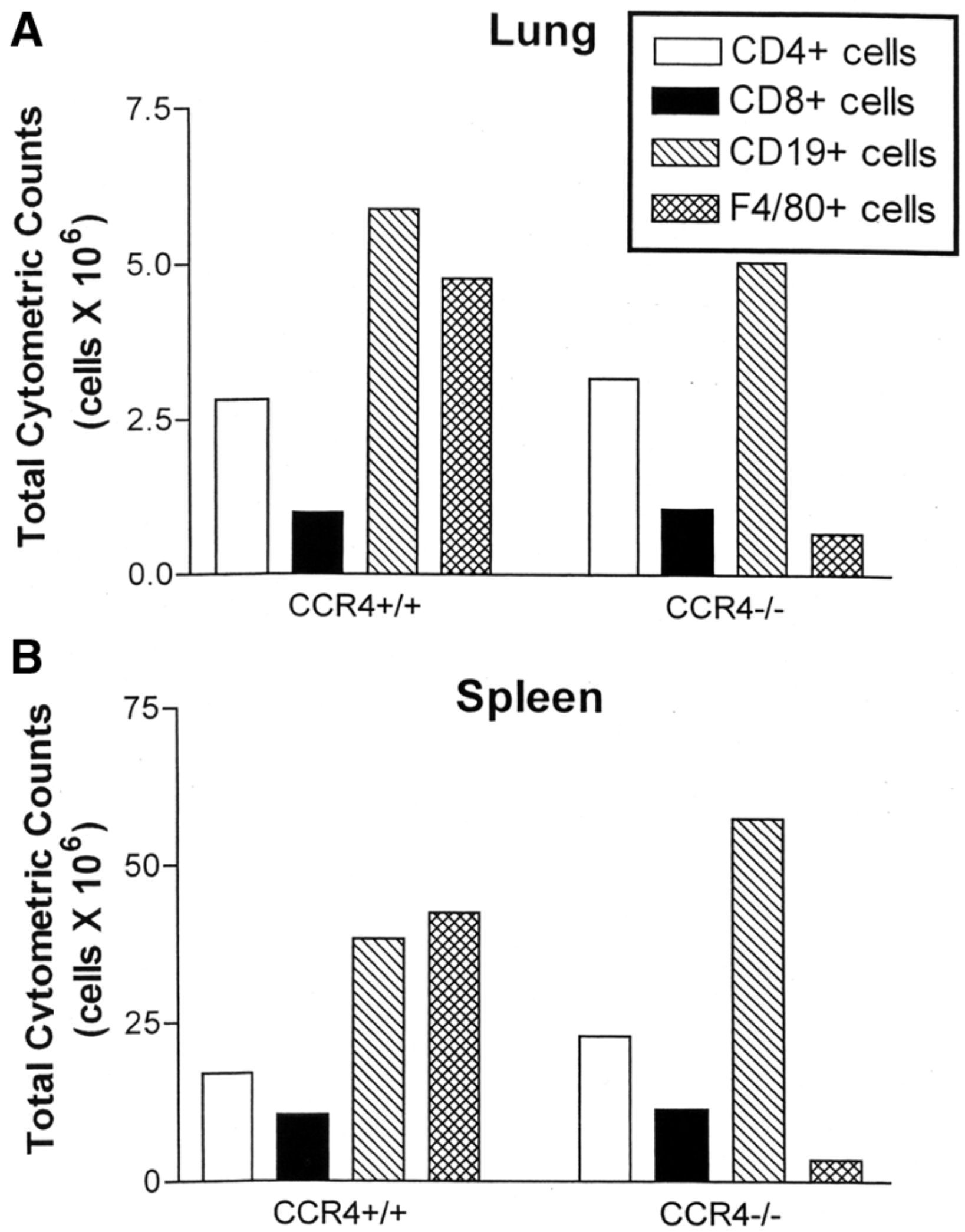

Figure 11. Flow cytometric counts for cells positive for CD4, CD8, CD19, and F4/80 at day 30 after conidia challenge in A. fumigatus-sensitized CCR4+/+ and CCR4-/- mice. Data are presented as pooled samples $(n=5)$. 
Fig. 12

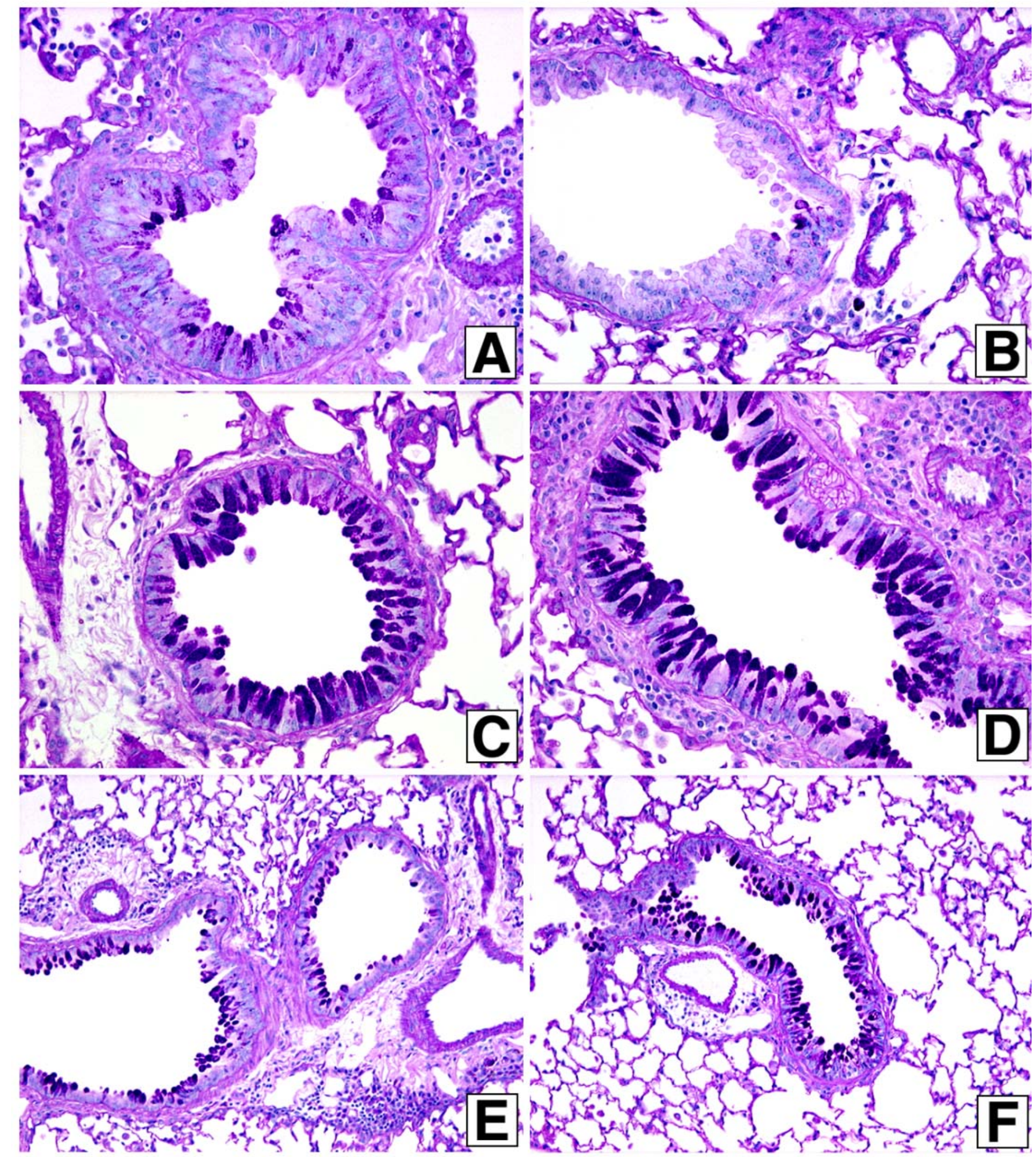

Figure 12. Representative photomicrographs of PAS-stained whole lung sections at days $3(\mathbf{A}, \mathbf{B}), 7(\mathbf{C}, \mathbf{D})$, and $30(\mathbf{E}, \mathbf{F})$ after conidia challenge in A. fumigatus-sensitized CCR4+/+ mice (A, C, E) and CCR4-/- mice $(\mathbf{B}, \mathbf{D}, \mathbf{F})$. PAS-stained goblet cells were prominent in the airways of both groups of mice at all times examined after conidia challenge. Original magnification was $400 \times(\mathbf{A}-\mathbf{D})$ or $200 \times(\mathbf{E}, \mathbf{F})$. 
Fig. 13

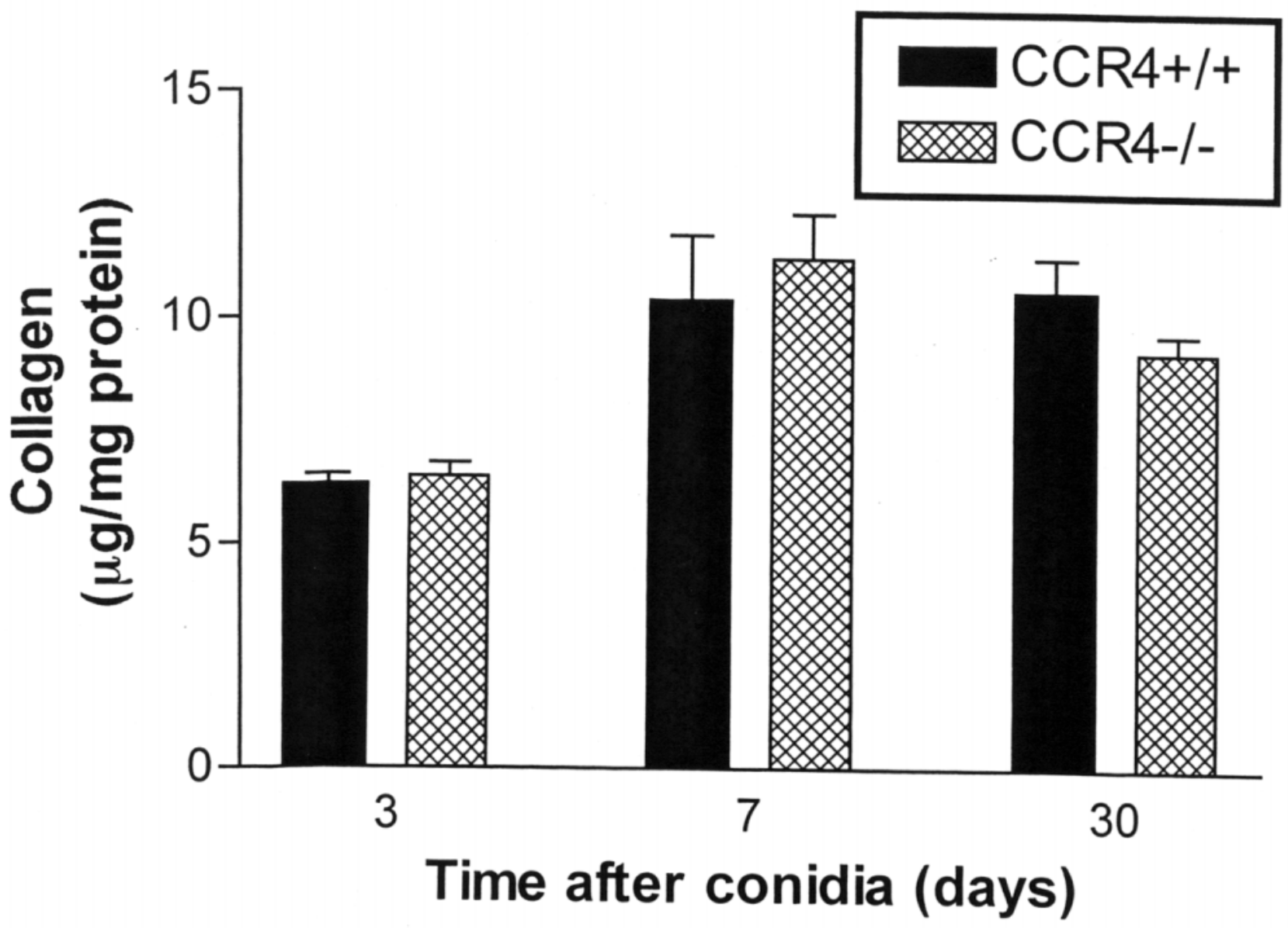

Figure 13. Total collagen levels in whole lung homogenates from A. fumigatus-sensitized CCR4+/+ and CCR4-/- mice at days 3,7, and 30 after conidia challenge. Total collagen levels were measured as described in Materials and Methods. Values are expressed as the mean \pm SE; $n=5-7 /$ group. 